\title{
LAS MEDIDAS DE LA SOCIEDAD
}

"Con la vara que midas, serás medido."

(Refrán popular.)

"He aquí el teorema fundamental de toda representación: sea un conjunto, produce un subconjunto que produce una ley que reproduce el conjunto; $y$ el conjunto, por ella, reproduce subconjuntos, y así indefinidamente. Que sea cerrado o alimentado en retorno sobre sí mismo, producción y reproducción, y eso explica el prefijo iterativo del vocablo representación."

(Michel SERREs.)

"Los controles jerárquicos surgen de una colección de elementos, pero actúan sobre individuos de la colección. La aparición espontánea de las constricciones colectivas debe ser, pues, una propiedad estadística de la colección, pero su comportamiento de control debe actuar sobre la dinámica de los elementos individuales."

(Howard H. Pattee.)

Jesús Ibáñez

El significado del título («Las medidas de la sociedad»), pues dos de sus términos («medidas», «de») son bisémicos, articula cuatro significados $(2 \times 2)$.

El término «medida» denota -en esta expresión- dos significados. «Tomar medidas del paro» - por ejemplo - puede significar: o bien tomar medidas al paro (medir el paro), o bien tomar medidas sobre el paro (para resolver el problema del paro).

El término «de» denota -en esta expresión- dos significados. Hay una novela policiaca que se titula $E l$ asesinato de mi tía. En los tres primeros capítulos, el sobrino cuenta cómo ha planeado el asesinato de su tía; en el cuarto capítulo, la tía cuenta cómo ha asesinado a su sobrino. El sobrino pasa de ser sujeto a ser objeto del asesinato. «Medidas de la sociedad» puede significar que la sociedad tome medidas o que a la sociedad le tomen medidas.

Tenemos, pues, cuatro significados:

Las medidas que yo -como investigador social - tomo de la sociedad:

1. Medidas a la sociedad que yo tomo: yo mido alguna dimensión de la sociedad.

2. Medidas sobre la sociedad que yo tomo: cuando yo mido alguna dimensión de la sociedad formo parte de un dispositivo de medidas so- 
bre la sociedad que yo —en realidad, los poderes que han requerido de mí la realización del estudio y a los que yo represento- estoy adoptando.

Las medidas que la sociedad se toma a través de mí:

3. Medidas a la sociedad que la sociedad se toma: pues cuando yo mido la sociedad, la sociedad se mide a través de mí.

4. Medidas sobre la sociedad que la sociedad se toma: pues el requerimiento explícito de la investigación y la conciencia de la necesidad de adoptar decisiones responde a una demanda social implícita (la demanda es del orden de la pregunta y el requerimiento es del orden de la respuesta).

Tenemos cuatro significados pero un solo sentido ${ }^{1}$. El que los dos significados de «medida» y de «de» se denoten con la misma palabra no es un azar: algo debe de haber en común entre ellos. En efecto. La primera medida sobre el paro es tomarle medidas al paro. Cuando yo mido la sociedad la sociedad se está midiendo a través de mí ( $y$, en algún sentido, me está midiendo a mí y está tomando medidas sobre mí: yo formo parte de la sociedad que mido). En todo proceso de comunicación, emisor (sujeto) y receptor (objeto) son intercambiables, la comunicación es una guerra que pone a los interlocutores frente a frente y los distribuye en vencedor (en este caso, el que habla o toma medidas)/vencido (en este caso, el que escucha o le son tomadas las medidas).

Los términos «medidas» $\mathrm{y}$ «de» no son, en realidad, bisémicos: lo que pasa es que su significado no es simple, sino complejo, y tenemos que utilizar con-

1 Significación: pertenece a la estructura, no envuelve necesariamente referencia al contexto, es una operación denotativa en un sistema digital. Sentido: pertenece al sistema, envuelve necesariamente referencia al contexto, es una operación connotativa en un sistema análogo. En términos freudianos, sentido tiene que ver con el proceso primario y significación con el proceso secundario; en términos lacanianos, significación tiene que ver con el orden imaginario y sentido con el orden simbólico; en términos levistrosianos, significación tiene que ver con el pensamiento científico y sentido con el pensamiento simbólico; en términos lingüisticos, significación tiene que ver con el componente semántico y sentido con el componente pragmático; en términos de teoría de la comunicación, significación tiene que ver con el almacenamiento de la información y sentido con su transmisión o funcionamiento. Ejemplo: la significación de una palabra la encontramos en -el almacén del- diccionario sin referencia a los contextos existencial ni lingüístico, pero el sentido de una palabra expresada aquí y ahora exige una referencia a todo el contexto existencial y a todo el contexto lingǘstico (por eso la traducción rigurosa es imposible). La signifícación tiene un valor (teórico) de verdad, el sentido tiene un valor (práctico) de supervivencia. Significación es lo que el lenguaje dice, sentido es lo que el lenguaje hace. El sentido aparece en una temporalidad irreversible, los significados en una temporalidad reversible (cíclica): por eso los significados pueden encerrarse en diccionarios, son recursos en el curso del sentido (son sentidos reciclables, cuando en un camino hay un bucle se vuelve a recorrer el mismo camino). 
ceptos complejos para tomar medidas del sistema hipercomplejo que es la sociedad: hipercomplejo, porque es un sistema complejo - esto es, reflexivo, que puede tomar medidas de sí- que incluye sistemas complejos - como yo, también reflexivo, pues puedo tomar medidas de mí.

Desembrollando este embrollo, esperamos aportar alguna luz a la vieja discusión sobre técnicas cuantitativas/cualitativas, al enfrentamiento entre los que trabajan en la numerería y los que trabajan en la palabrería.

\section{¿QUE SE MIDE? TIPOS DE MEDIDA}

Podemos considerar la medición en un sentido amplio y en un sentido estricto. En un sentido amplio, medir es sustituir algo por un número.

Hay cinco niveles de medición:

i) Nominal: clasifica.

ii) Ordinal: ordena.

iii) Interval: mide, sin cero ni uno.

iv) De razón: mide, sin cero pero con uno. Medición en sentido estricto.

v) Absoluto: mide, con cero y con uno (cuenta).

Veremos que a nivel social hay dos modelos de dispositivos de medición: el dispositivo nominal de la lengua (que produce valor de cambio semántico) y el dispositivo numeral de la moneda (que produce valor de cambio económico). A los niveles $i$ ) e ii) es más accesible el dispositivo nominal de la lengua (por eso la sociología, donde casi nunca son pertinentes niveles más elevados de medición, puede prescindir en gran medida de los números). A los niveles $i i i), i v)$ y $v$ ) es más accesible el dispositivo numeral de la moneda ${ }^{2}$.

2 El número es más exacto que la palabra. Esta es su grandeza y su miseria. En general, tiene -como veremos- más valor de supervivencia la anexactitud que la exactitud. Por su exactitud, puede operar con números un algoritmo o robot. Por su anexactitud, sólo puede operar con palabras un sujeto humano (a no ser que las palabras se hagan exactas, y entonces ya no son palabras). Un sistema cerrado funciona con operadores exactos, un sistema abierto sólo opera con operadores anexactos: sólo un operador anexacto puede integrar el ruido del entorno (así se producen slempre la evolución y las revoluciones: una mutación es un error integrado - del código genético-, un pensamiento es un error integrado - del códilo lingüístico-). Las técnicas cuantitativas de investigación son objetivas, las técnicas cualitativas de investigación son -en parte- subjetivas (en las segundas, el investigador piensa; en las primeras, no). El uso de algoritmos o robots en las tareas de investigación ha supuesto la extensión del concepto de medición (con la contrapartida de una pérdida de comprensión): para que un ordenador opere tenemos que cuantificar todas las variables aunque sea en un sentido muy débil. Cuando un ordenador maneja palabras las maneja como números, cuando un sujeto humano maneja números los maneja como palabras. Sólo hay, propiamente, medición a partir del nivel iii): sólo a partir de ese nivel, se manejan las propiedades extensivas o cuantitativas de los conceptos o conjuntos. 
En ambos casos, tenemos que investigar la sintaxis (inmanente), la semántica (trascendente, en la perspectiva de la representación) y la pragmática (trascendente, en la perspectiva de la voluntad).

\section{Aspectos sintácticos de la medición}

"Un investigador cuantitativo es el que no sabe lo que hace, un investigador cualitativo es el que sabe lo que hace."

(JesúS IвÁÑEZ.)

Cuando cuantificamos - que es el significado amplio que hoy damos al término «medida»- sustituímos lo que cuantificamos por cifras; pero esas cifras no son realmente números, aunque se escriban como ellos, hasta el nivel de razón de medida (a este nivel - medida en sentido estricto- las cifras son números reales).

Para que una medición tenga sentido debe poder establecerse una cierta correspondencia entre el campo de objetos sustituidos y el campo de cifras (o de números) sustituyentes. Sólo si entre los objetos se dan ciertas relaciones puede realizar con ellos ciertas operaciones un sujeto. Si las operaciones que realiza el sujeto son coherentes con las relaciones entre los objetos, el sujeto puede hacer aunque no sepa lo que hace. Cuando el sujeto sabe lo que hace se ha transformado en matemático: matemática no es más que la autoconciencia de la propia actividad (de la actividad real y - sobre todo- de la actividad posible: el universo matemático es más rico que el universo real) ${ }^{3}$. Podemos transformar la frase que encabeza este capítulo en esta otra: un cualitativo es un cuantitativo que sabe matemáticas.

El lenguaje matemático es un subconjunto del lenguaje. En matemáticas hay dos conceptos centrales: el número y el espacio. A partir de estos conceptos se han desarrollado, por un lado las álgebras, por otro lado las geometrías ${ }^{4}$. Pero las álgebras y las geometrías constituyen refinamientos del len-

3 Dice Spencer-Brown (Laws of form, E. P. Dutron, 1979): "Un aspecto reconocible del avance en matemáticas consiste en el avance de la autoconciencia de lo que estamos haciendo, gracias a lo cual lo cubierto se transforma en abierto. La matemática es, en este aspecto, psicodélica" (pág. 85). Y dice en otro lugar: "A menudo me ha chocado el alineamiento aparente de las matemáticas con la teoría psicoanalítica. En cada una de estas disciplinas tratamos de encontrar, por una mezcla de contemplación, representación simbólica y comunicación, qué es lo que ya conocemos. En matemáticas, como en otras formas de autoanálisis, no tenemos que ir explorando el mundo físico para encontrar lo que estamos buscando" (pág. XXIII).

4 Espacio y número son dos aspectos de lo mismo: constituyen dos conceptos complementarios. La complementariedad ha aparecido en microfísica cuando dos aspectos de algo (como el aspecto corpuscular y el aspecto ondulatorio de las partículas y ondas) no pueden manifestarse simultáneamente pero sí sucesivamente. La historia de las matemáticas, desde que se encontraron las geometrías egipcia y griega, es la historia -entre otras cosas- de la aplicación de los números a los espacios (véase Jesús IBÁñez, Geometría del poder y espacios de subversión, 1982, inédito). 
guaje. Sus orígenes están en Grecia y Egipto. La escritura egipcia era jeroglífica, la griega era alfabética. La representación jeroglífica es un análisis de la cosa - un dibujo estilizado-; en este sentido es una protogeometría. La representación alfabética es un análisis del signo - del flujo fónico-; en este sentido es una protoálgebra ${ }^{5}$. La escritura jeroglífica es análoga, la escritura alfabética es digital ${ }^{6}$. De este doble origen derivan las corrientes intuicionistas (de las geometrías representadas analógicamente) y formalistas (de las álgebras construidas digitalmente) de las matemáticas. La escritura jeroglífica es un análisis de objetos, la escritura alfabética es un análisis de la actividad del sujeto; de ahí la mayor potencia lógica de ésta, pues descansa en una reflexividad de nivel superior. Cuando la geometría se libera de la representación (cuando el espacio es ocupado por el número) —aventura que empieza con el encuentro de los matemáticos egipcios y griegos- pone en juego todas sus propiedades creativas.

Vamos a ver, en este parágrafo, las propiedades iógicas y matemáticas que deben tener los objetos para que puedan ser medidos a los distintos niveles (para que se correspondan con las propiedades de las cifras o números a cada nivel). Primero en un contexto algebraico, luego en un contexto geométrico. En el parágrafo siguiente volveremos al lenguaje, que es el contexto genético y estructural del lenguaje matemático; pasaremos de la sintaxis - formal- a la semántica (lo que dice el lenguaje) y a la pragmática (lo que hace el lenguaje)

\section{a) Clasificación}

Un conjunto de objetos se puede distribuir en clases si entre ellos se dan las siguientes relaciones:

1.1. Si se dan reflexividad ( «aRa»), simetría ( $\ll a R b \rightarrow$ bRa») y transitividad ( $\ll \mathrm{aRb} \cap \mathrm{bRc} \rightarrow \mathrm{aRc})$, los podemos distribuir en clases de equivalencia. Por ejemplo, la relación «colega de...»: Juan es colega

5 Michel Serres, Le passage du Nord-Ouest, París, Minuit, 1982, pág. 180. El parentesco entre el número y la letra (su naturaleza común de cifras) no está sólo en en origen, sino también en el término; véase, por ejemplo, la binarización actual de los números (álgebra de Boole, que los reduce a combinaciones de 0 y 1) y de las letras (alfabeto Morse, que las reduce a combinaciones de puntos - . - y rayas $--\cdots$.

6 Análoga: en términos continuos de más o menos (es un análisis de las similitudes). Digital: en términos discretos de sí o no (es un análisis de las diferencias -en cuanto oposiciones-). Una figuración análoga se pega a lo figurado, una figuración digital se despega de lo figurado (es la diferencia entre modelos analógicos y generativos). La digitalización permite ir más allá en dirección a lo posible, pero lo digital sólo cobra sentido en el contexto de lo análogo. De lo análogo proceden los fines, de lo digital proceden los medios: por ejemplo, no se puede comunicar (digitalmente) nada si no hay deseo (análogo) de comunicar (la comunicación es antes que nada fática - una resonancia análoga entre los interlocutores-). Por lejos que vayamos en dirección al formalismo, no podemos renunciar a la intuición. 
de Juan; si Juan es colega de Pedro, Pedro es colega de Juan; si Juan es colega de Pedro y Pedro es colega de Luis, Juan es colega de Luis ${ }^{7}$.

1.2. Si se dan reflexividad, antisimetría ( $\ll a R b \rightarrow \sim$ bRa») y transitividad, los podemos distribuir en clases de orden - jerárquicas o encajadas - Por ejemplo, la relación «subordinado a...»: Juan está subordinado a Juan ${ }^{8}$, si Juan está subordinado a Pedro, Pedro no está subordinado a Juan; si Juan está subordinado a Pedro y Pedro está subordinado a Luis, Juan está subordinado a Luis.

Podemos considerar la clasificación como el grado cero de la medida (medida nominal).

\section{b) Medición}

Podemos considerar tres formas de cantidad: intensiva, extensiva no métrica y extensiva métrica ${ }^{9}$. Sólo son medibles - a niveles superiores al cero- los conjuntos ordenados; no hay posibilidad de medición si no hay sentido.

En un concepto o conjunto son complementarias la extensión (elementos que comprende) y la comprensión (propiedades comunes a esos elementos). La cualidad se refiere al aspecto de la comprensión, la cantidad se refiere al aspecto de la extensión. Pero, desde el punto de vista extensional, podemos definir cantidades intensivas y cantidades extensivas.

\section{b.1) Cantidad intensiva}

La podemos definir desde las clases y desde las relaciones. Desde las clases: supongamos la clase $A$ (obreros) y la clase $B$ (obreros textiles), la segunda encajada en la primera $(« A<B »)$; esta relación nos permite distribuir el conjunto A en dos subconjuntos, B y B' (su complementario: obreros no textiles). Hay reflexividad (los textiles son textiles), antisimetría (todos los textiles son obreros pero no todos los obreros son textiles) y transitividad (si los de «Fabra y Coats» son textiles y los textiles son obreros, los de «Fabra y Coats» son obreros). Lo único que sabemos es que la parte es menor que el todo $\left(« B<A \cap B^{\prime}<A »\right)$; no sabemos si una parte es mayor o menor que otra

7 "Ser colega de ..." es la forma más general de relación que genera clases de equivalencia en el campo de las ciencias sociales: son colegas los que, en el contexto de la misma ley, adoptan la misma lectura (semántica) o la misma elección (pragmática).

$8 \mathrm{El}$ orden perfecto es flexible (por reflexivo). La ética burguesa introduce la flexibilidad al introducir la reflexividad: cada uno se alimenta de sí mismo (libre examen) y cada uno se procrea a sí mismo (cada uno es hijo de sus obras). Un orden rígido es -como el orden burocrático- no reflexivo.

9 Jean PIAGET, Introducción a la epistemología genética 1. El pensamiento matemático, Barcelona, Paidós, 1975, págs. 85 ss. 
parte (si hay más o menos textiles que no textiles). Desde las relaciones: supongamos la relación a (Juan está subordinado a Pedro) y la relación $a$ ' (Pedro está subordinado a Luis). Hay reflexividad (Juan está subordinado a Juan), antisimetría (si Juan está subordinado a Pedro, Pedro no está subordinado a Juan) y transitividad ( si Juan está subordinado a Pedro y Pedro está subordinado a Luis, Juan está subordinado a Luis). De la transitividad se deduce que Juan está subordinado a Luis $\left(a+a^{\prime}=b\right)$. Sabemos que hay más diferencia Entre Juan y Luis que entre Juan y Pedro, pero no sabemos cuánta más diferencia hay (como antes sabíamos que había más obreros que de «Fabra y Coats» pero no sabíamos cuántos más había).

La cuantificación intensiva sólo admite las cantidades: uno, todos, algunos, ninguno. Es propia del cálculo lógico, pero no del cálculo matemático ${ }^{10}$. Esto ccurre porque tratamos con propiedades no aditivas (en el campo de las relaciones) o porque, tratando con propiedades aditivas, no tenemos suficiente información sobre la extensión de los conjuntos (en el campo de las clases). La «subordinación» es una propiedad no aditiva; no se pueden sumar las subordinaciones (no tendría sentido decir que la subordinación de Juan a Luis es igual a la subordinación de Juan a Pedro más la subordinación de Pedro a Luis). La masa, por ejemplo, es una propiedad aditiva; la masa de un camión cargado es igual a la tara (= camión vacío) más la carga. La densidad, por ejemplo, es una propiedad no aditiva; si el hierro flota en mercurio y no flota en agua, podemos decir que el mercurio es más denso que el agua, pero si añadimos agua y mercurio (como hemos añadido la tara y la carga) no obtenemos un líquido de densidad igual a la suma de las dos (de hecho, si se mezclaran, la densidad sería intermedia entre las dos densidades).

Para que la medición intensiva sea posible, además de reflexividad, antisimetría y transitividad debe darse la siguiente relación ":

2) $(\mathrm{A}<\mathrm{B}) \mathrm{U}(\mathrm{A}>\mathrm{B}) \mathrm{U}(\mathrm{A}=\mathrm{B})$ : o una u otra de estas relaciones. No hay tercero posible; o es igual o no es igual, y si no es igual, o es menor o es mayor.

A nivel ordinal (nivel uno de medida) se produce una medición intensiva.

\section{b.2) Cantidad extensiva}

La cantidad extensiva puede ser no métrica o métrica.

Estos dos tipos de cantidad tienen en común: hay una relación cuantitativa entre las clases $\mathrm{B}$ y $\mathrm{B}^{\prime}$ o entre las relaciones $a$ y $a^{\prime}$; sabemos si una parte (además de ser menor que el todo) es mayor o menor o igual que la otra parte.

10 La teoría aristotélica del silogismo se funda en una cuantificación intensiva. Después de Spencer-Brown (op. cit.) no deberíamos hablar de diferencias entre la lógica y la matemática. Spencer-Brown ha aritmetizado el cálculo lógico, explicitando la aritmética implícita en el álgebra de Boole.

11 Morris Cohen y Ernest NageL, Introducción a la lógica $y$ al método científico, tomo 2, Amorrortu, 1968, pág. 124. 
En un caso sabemos si hay más textiles o no textiles, en el otro caso sabemos si Juan está subordinado a Pedro más o menos o igual que está Pedro a Luis (por ejemplo, según el repertorio de obligaciones que les pueden imponer).

\section{b.2.1) Cantidad extensiva no métrica}

Cuando estamos en presencia de una serie de encajes del tipo «casi todos», sabemos que un conjunto es mayor que el conjunto complementario. "Casi todos los españoles son blancos»; luego blancos $(\mathrm{B})$ es mayor que no blan$\cos \left(\mathrm{B}^{\prime}\right)$.

Cuando estamos en presencia de una serie de relaciones convergentes sucede lo mismo. Si dos líneas convergen, la serie de las paralelas que miden la distancia entre ellas está ordenada $(A>B>C>\ldots)$, pero también están ordenadas las diferencias entre ellas ( $\mathrm{si}$ las paralelas son equidistantes, sus diferencias de longitud son iguales).

En ambos casos es posible una representación gráfica (análoga), aunque no sea posible una representación numérica (digital).

\section{b.2.2) Cantidad extensiva métrica}

Para que podamos cuantificar (y no sólo representar gráficamente) es preciso que las partes complementarias puedan reducirse a una serie de iteraciones de una unidad que les es común: unidad «ser humano» en el caso de los obreros, unidad «centímetro» en el caso de las paralelas. La primera es necesaria (no hay otra unidad posible), la segunda es arbitraria (cabría una unidad múltiplo - «decímetro»- o divisor - «milímetro»- u otra unidad cualquiera que no guarde con ella una relación simple — como «pulgada»-).

Deben darse, además de las indicadas antes, las siguientes relaciones (que son los requisitos de la aditividad):

$$
\left\{\begin{array}{l}
\text { 3) }(A+B=C) \rightarrow(B+A=C) \text { conmutatividad } \\
\text { ( 4) }(A=B) \rightarrow[(A+D)>B] \\
\text { 5) }[(A=B) \cap(C=D)] \rightarrow[(A+C)=(B+D)] \\
\text { (6) }(A+B)+C=A+(B+C) \text { asociatividad }
\end{array}\right.
$$

\section{b.2.2.1) Medición fundamental y derivada}

El carácter aditivo de ciertas propiedades fundamentales (longitud, masa y tiempo, por ejemplo) permite mediciones fundamentales a nivel físico.

Pero hay casos en los que, no siendo posible una medición fundamental, es posible una medición derivada. Así es posible asignar mediciones métricas a ciertas propiedades intensivas o extensivas no métricas.

Cuando existe una correlación entre propiedades no métricas y propiedades métricas es posible una medición derivada. Por ejemplo, la densidad y la temperatura son propiedades intensivas no medibles métricamente. Pero la 
densidad llega a ser medible de forma derivada si descubrimos que la relación peso/volumen es constante (densidad = peso/volumen); la temperatura llega a ser medible de forma derivada si descubrimos que - por dilatación-- es proporcional a la longitud (de ahí el termómetro de mercurio). La relación $\mathrm{V}=1^{2}$ (superficie del cuadrado en función del lado) permite medir un espacio extensivo.

\section{b.2.2.2) Unidad y origen}

Una medición por encima del nivel ordinal (esto es, una medición de orden por lo menos dos) exige una unidad de medida y un origen. Pueden ser arbitrarios o necesarios.

\section{b.31, Resumen}

Podemos resumir lo visto hasta ahora en el cuadro de la página siguiente.

\section{c) Algebras y geometrias para la medida}

Una medición es una operación puntual (empírica). Pero carecerá de sentido si no se incluye en un universo de discurso (teórico). Hay que conjugar las dos dimensiones clásicas de la función veritativa: adecuación a la realidad y coherencia del discurso.

¿Qué hacemos con las cifras obtenidas como resultado de las mediciones?

Sabemos lo que podemos hacer cuando esas cifras son números reales: a partir del nivel de razón. Pero, ¿qué entidad tienen las cifras obtenidas a niveles inferiores?

Para que la matematización en ciencias sociales tenga sentido ha de haber alguna correspondencia entre tres planos: primero, entre los objetos sociales y los conceptos sociológicos; segundo, entre los conceptos sociológicos y los conceptos matemáticos. El freno a la matematización aparece en los tres planos; los objetos sociales no admiten casi nunca - por no decir nunca- una matematización semejante a la que admiten los objetos físicos (que, al menos a nivel mesofísico, admiten una cuantificación extensiva métrica) y los objetos vitales (que, por lo menos, admiten una cuantificación extensiva no métrica); los conceptos sociológicos están muy poco elaborados, ni dan razón de los objetos sociales (en una dimensión empírica) ni son coherentes (en una dimensión teórica); no hay —o no ha habido hasta hace poco- teorías matemáticas que puedan acoger a los objetos sociales y a los conceptos sociológicos.

A título meramente indicativo, vamos a examinar el repertorio de estructuras matemáticas que podrían constituir universos teóricos de discurso para las cifras que expresan el resultado de las mediciones. 


\section{c.1) Estructuras algebraicas}

Vamos a considerar separadamente las que pueden acoger las cifras procedentes de mediciones intensivas y las cifras procedentes de mediciones extensivas métricas.

\section{CUADRO 1}

Niveles de medición

a) Operaciones:

Clasificación

Ordenación

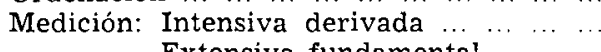

Extensiva fundamental $\ldots \ldots \ldots$

Recuento

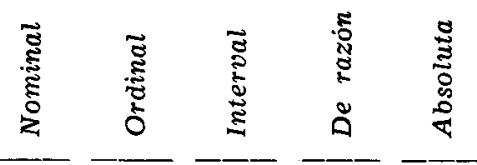

$\mathbf{X}$

$\begin{array}{cccc}\mathbf{X} & \mathbf{X} & \mathbf{X} & \mathbf{X} \\ \mathbf{X} & \mathbf{X} & \mathbf{X} & \mathbf{X} \\ & \mathbf{X} & & \\ & & & \end{array}$

b) Origen:

No

$\mathrm{x} \quad \mathrm{x}$

Sí: Arbitrario

Necesario

$\mathbf{x}$

$\mathrm{x} \quad \mathrm{x}$

c) Sentido:

No

$\mathbf{X}$

Sí

$\mathrm{x} \quad \mathrm{x} \quad \mathrm{x}$

d) Unidad:

No ...

$\mathrm{x} \quad \mathrm{X}$

Sí: Arbitraria

Necesaria

e) Relaciones interpretables:

Igual, no igual

$\mathbf{x}$

$\begin{array}{llll}\mathbf{X} & \mathbf{X} & \mathbf{X} & \mathbf{X} \\ \mathbf{X} & \mathbf{X} & \mathbf{X} & \mathbf{X} \\ & \mathbf{X} & \mathbf{X} & \mathbf{X} \\ & & \mathbf{X} & \mathbf{X} \\ & & & \end{array}$

Diferencias iguales

Razones iguales

Todas

$\mathrm{X}$

f) Transformaciones legitimas:

Las que conservan igual y no igual...

$\mathbf{x}$

Las monótonas (conservan mayor y menor).

Las de tipo " $a+b x$ " (cambio unidad $y$ origen)

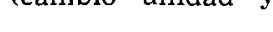

Las de tipo " $b x$ " (cambio de unidad)

$\mathbf{x}$

$\mathbf{X}$

Ninguna

$\mathrm{x}$

$\mathrm{x} \quad \mathrm{x}$

$\mathbf{x}$ 


\section{c.1.1) Redes, agrupamientos y grupos}

a) Piaget ${ }^{12}$ ha construido una estructura matemática («agrupamiento») que incluye el conjunto de relaciones intensivas de parte a todo. Tiene estas cinco propiedades:

1." Dos operaciones del conjunto se reúnen en una nueva operación: es el fundamento de la transitividad.

2." Cada operación puede invertirse: es el fundamento de la reversibilidad.

3." Tres operaciones compuestas entre sí son asociativas: es el fundamento de la posibilidad de llegar al mismo resultado por distintos caminos.

4. La composición de una operación con su inversa produce una «operación idéntica general» (que equivale a la ausencia de operación).

5." Una operación compuesta consigo misma o con las operaciones que la incluyen mantienen constantes a estas últimas («operaciones idénticas especiales»): es el fundamento de la tautología $(« A+A=A »)$ (frente a la iteración de los números - $\mathrm{A}+\mathrm{A}=2 \mathrm{~A} »-$ ).

b) Esta estructura (el «agrupamiento») es intermedia entre una estructura más débil (la «red») y una estructura más fuerte (el «grupo»):

- Una red es un sistema semiordenado tal que dos elementos cualesquiera tienen un límite superior (menor mayorante, puede ser la clase común más pequeña que incluye a las clases analizadas) y un límite inferior (mayor minorante, puede ser la parte común a las dos clases de unión). La red tiene una reversibilidad limitada ${ }^{13}$; añadiéndole la segunda con. dición - inversión de operaciones - tenemos una reversibilidad ilimitada (el agrupamiento es una red reversible).

- Si al «agrupamiento» le quitamos la quinta condición - tautologíastendremos el «grupo» de las adiciones disyuntivas propio del álgebra de Boole (podemos operar con partes disjuntas).

c) Estas estructuras permiten manejar las cifras obtenidas en las operaciones de medición a niveles nominal y ordinal. Por ejemplo:

- Mediante «redes» se puede analizar la actividad inconsciente.

12 Piaget, op. cit., págs. 88-89.

13 Víctor Gómez-Pin y Javier EcheverRía, en Limites de la conciencia y el matema (Madrid, Taurus, 1983), proponen el análisis mediante grafos de los sueños. De momento, analizan el sueño de la inyección de Irma. La debilidad de las estructuras de red es una ventaja: una estructura más fuerte hubiera racionalizado el inconsciente (pasando de la conexión entre términos a la conexión entre proposiciones). El pensamiento inconsciente es más débil que el pensamiento consciente: por eso es más potente, pues - al no estar encasillado- puede absorber el ruido. 
- Mediante "grupos de disyunciones» se puede analizar la actividad consciente $^{14}$.

- Mediante «agrupamientos» se puede analizar la actividad práctica no consciente (que conjuga lo inconsciente y lo consciente) ${ }^{15}$.

\section{c.1.2) El número}

a) Al transformar los elementos en unidades se puede agotar un conjunto por iteración de la unidad, lo que permite comparar no sólo las partes con el todo sino también las partes entre sí.

El número conjuga un componente cardinal (clases lógicas) y un componente ordinal (relaciones asimétricas).

b) El campo del número se ha ido extendiendo a partir de los enteros positivos (naturales); la operación de restar (un número mayor de un número menor) obligó a construir los negativos; la operación de dividir (un número por otro no divisor) obligó a construir los fraccionarios; la operación de extraer raíces cuadradas de números positivos (inconmensurabilidad de la diagonal y el lado del cuadrado) obligó a construir los números irracionales; la operación de extraer raíces pares de números negativos (para solucionar ecuaciones de grado par) obligó a construir los números imaginarios - componente de los números complejos-.

c) Con los números complejos nos separamos de la realidad, en sentido actual, para la que quedan los números reales. La invención de los números complejos es la salida de una situación paradójica. Constituyen paradojas, una sentencia autorreflexiva, una función que es función de sí misma. La ecuación $\left\langle\mathrm{x}^{2}+1=0 »\right.$ puede transformarse en $« \mathrm{x}=-1 / \mathrm{x} »(x$ función de $x)$; la solución debe ser una unidad, pero no es la unidad positiva ni la unidad negativa. Bonelli, en un golpe de genio, decretó la existencia de un tercer tipo de unidad, la unidad imaginaria $(\ll i=\sqrt{-1 »)}$ : esa unidad trajo a la existencia los números imaginarios, componente de los números complejos. Cuando -recientemente- Spencer Brown ${ }^{16}$ explicita la aritmética implícita en el álgebra de Boole, se encuentra en una situación semejante; la solución de las ecuaciones de grado par es también paradójica, no valen el valor positivo (verdad) ni el valor negativo (falsedad), por lo que debe inventar un tercer valor (imaginario). El pensamiento complejo incluye valores imaginarios, imaginarios porque no están en el espacio sino en el tiempo, en uno de los futuros posibles. La lógica se abre a lo posible: real en cuanto virtual.

14 El cálculo mediante ordenador utiliza el álgebra de Boole.

$15 \mathrm{El}$ "agrupamiento" ha sido construido por Piaget para analizar la lógica del pensamiento práctico.

$16 \mathrm{Op}$. cit. 
d) Los números complejos no tienen representación gráfica: si queremos representar la realidad en el espacio ${ }^{17}$. Pero esa representación fue posible mediante otros dos golpes de genio, ambos equivalen a una dinamización (un paso de la representación como copia a la representación como programa - reproducción-). El primer paso fue la consideración de vectores con dirección: $i$ era un operador de giro. El segundo paso (Hamilton) decretó la existencia de cuaterniones: los cuaterniones son el resultado de multiplicar dos birradiales (relaciones entre vectores de origen común). Esta multiplicación (lo mismo que la adicción esférica) es no conmutativa ${ }^{18}$.

e) Despegados de lo real actual, los números se acercan a lo infinitamente pequeño y a lo infinitamente grande. Lo infinitamente pequeño es alcanzado por el cálculo infinitesimal; se alcanza como relación entre dos cantidades decrecientes ${ }^{19}$. Lo infinitamente grande es alcanzado por la matemática transfinita de Cantor. Con los transfinitos desaparece la conexión entre cardinalidad y ordinalidad; hay una correspondencia biunívoca entre el todo y la parte (por ejemplo, el conjurito de los números enteros es coordinable con el conjunto de los pares). La correspondencia entre el todo y la parte es una correspondencia reflexiva y produce una equivalencia multiplicativa - no aditiva- Los ordinales transfinitos son tipos de orden, sistemas multiplicativos de relaciones asimétricas. Los cardinales transfinitos son clases. A un mismo cardinal transfinito pueden asociarse una infinidad de ordinales transfinitos. Por su reflexividad y su multiplicabilidad la matemática transfinita es especialmente adecuada para el cálculo de la actividad de los sujetos, en particular (un sujeto es un bucle de reflexividad en un conjunto), y para la representación de sistemas hipercomplejos, en general (sistemas con componentes reflexivos: producto de la multiplicación de esos componentes) ${ }^{20}$.

f) Estas estructuras permiten manejar las cifras (ya números) obtenidas a partir de mediciones interval, de razón o absoluta.

\section{c.2) Estructuras topológicas}

Hay también estructuras que permiten manejar las cifras procedentes de mediciones extensivas no métricas.

17 En la Galaxia Gutenberg el modelo de inteligibilidad es la aplicación sobre un plano -esquema de la hoja impresa-. En castellano: "explicar" (=desplegar), llevar la madeja o la maraña a un plano. En inglés: "explain" (=explanar), proyectar sobre un plano.

18 Esta no conmutatividad ha permitido su utilización en microfísica.

19 La relación o razón subsiste cuando se desvanecen los términos. El cálculo diferencial es el término de un proceso: primero se sustituyen las cosas por sus imágenes (lo imaginario), luego se sustituyen las imágenes por conceptos (lo simbólico), finalmente se formalizan los conceptos (hasta que no queda más que una relación o razón). Hegel celebró la invención del cálculo infinitesimal: pues todo lo real se transformaba en racional.

20 Daniel Srbony (Le nom et le corps, Seuil, 1974) aplica la matemática de Cantor a la concepción psicoanalítica del sujeto deseante. 
Vamos a considerar separadamente el grupo fundamental de las geometrías euclideanas y las geometrías no euclideanas.

\section{c.2.1. Grupo de las geometrías euclideanas}

a) Hay un conjunto de estructuras topológicas que, a partir del grupo de los desplazamientos de Klein, se ha integrado en una estructura más general.

Podemos considerar desde la estructura más general a la menos general:

- Teoría de los conjuntos de puntos: el único invariante es el número de puntos (cuando, por ejemplo, disparamos un cartucho de perdigones).

- Topología - grupo de las homeomorfías-: se conserva también el orden entre los puntos (cuando, por ejemplo, arrugamos un papel o estiramos una goma).

- Geometría proyectiva: se conservan también la recta y las relaciones no armónicas (cuando, por ejemplo, representamos un paisaje en una fotografía).

- Geometría de las afinidades: se conservan también las paralelas (es como una proyección en paralelo, sin punto perspectivo).

- Geometría de las similitudes: se conservan también los ángulos (cuando, por ejemplo, hacemos una maqueta a escala).

- Geometría euclideana propiamente dicha - grupo de los desplazamientos-: se conservan también las distancias (cabe desplazar, invertir, girar, etc.).

Hay un encaje entre estas estructuras: cada grupo es un subgrupo del grupo anterior.

b) También los niveles de medida encajan unos en otros. Es posible una cierta correspondencia entre niveles de medida y estructuras topológicas; se podrían tal vez aplicar:

- Las cifras resultado de medidas nominales a la teoría de los conjuntos de puntos.

- Las cifras procedentes de medidas ordinales a la topología ${ }^{21}$.

- Las cifras procedentes de medidas intervales a la geometría de las afinidades ( si consideramos como no interpretable el origen) o a la geometría proyectiva ( $\mathrm{si}$ consideramos como interpretable el origen).

- Las cifras procedentes de medidas de razón a la geometría de las similitudes.

- Las cifras procedentes de medidas absolutas a la geometría euclideana.

21 Desde Thom, la topología se ofrece como la rama más fecunda de las matemáticas para el orden vital y el orden social. 
c) En el orden de las relaciones sociales difícilmente podremos pasar del nivel ordinal - de ahí la importancia de la topología como modelo de matematización-. No hay distancia, o al menos no hay distancia métrica, y - desde luego- no hay ángulos.

\section{c.2.2) Geometrías no euclideanas}

a) Estas geometrías empezaron con la crítica del quinto postulado (Wallis, Gauss, Lobatchevsky, Riemann...). Su construcción ha articulado dos vías ${ }^{22}$ :

- Despegándose de la experiencia, se introduce una primera inversión reflexiva (en la perspectiva del sujeto). Se pueden eliminar o cambiar axiomas, primero discutibles, luego evidentes; el primer paso lo da, por ejemplo, Riemann (con la sustitución del quinto axioma); el segundo paso lo da, por ejemplo, Veronese (que, descartando la relación métrica elemental -evidente-, construye la geometría no arquimedeana).

- Volviendo críticamente sobre la experiencia, se introduce una segunda inversión reflexiva (en la perspectiva del objeto). Los matemáticos empiezan a preguntarse si la realidad es en realidad euclideana y si una percepción más rigurosa no llevaría a descubrir la naturaleza no euclideana de la realidad (de hecho, geometrías —incluso las no arquimédicas- que son construcciones teóricas arbitrarias - arbitrarias en su existencia, no en su coherencia- han constituido espacios teóricos de acogida de descubrimientos empíricos: tal fue el caso sonado de la teoría de la relatividad).

La realidad es, en dirección a lo supraglobal, no euclideana (riemanneana), en dirección a la infralocal, no arquimedeana (veroneseana). Basta conque me quite yo.

Las estructuras local y global son contradictorias entre sí. Una esfera puede construirse pegando trozos de plano: de los planos tangentes a cada uno de los puntos de su superficie. Pero no es posible la desconstrucción; la esfera no es deplegable sobre el plano. El espacio es euclideano localmente y no euclideano globalmente; a cada punto del espacio no euclideano puede pegarse un espacio euclideano tangente (esos espacios locales euclideanos son medibles, pero el espacio global no euclideano no es medible). Sólo una concepción riemanneana del espacio da razón de las variedades locales; el espacio euclideano es homogéneo (es un espacio trabajado por un poder al que vo represento). La naturaleza euclideana y medible del espacio global es sólo un requisito lógico para que la representación - -y la medición - sea posible. La geometría euclideana y la geometría no euclideana son dos perspectivas complementarias sobre el espacio: es euclideano sumergido en un contexto (operación necesaria

22 Piaget, op. cit., págs. 217-218. 
para que yo como observador pueda verlo y manejarlo desde fuera), es no euclideano extraído del contexto. Hermann Weil construyó una variedad abstracta, componiendo un espacio no euclideano pegando trozos euclideanos. El espacio es en-sí no euclideano aunque sea para-mí euclideano. Ya Zenón nos advirtió contra la tentación de sumergir el espacio (¿dónde?; el espacio, decía, no existe, porque si existiera estaría sumergido en otro espacio y así hasta el infinito). La hipótesis en la que se funda la representación, llenar lo global por iteración de una singularidad local, no se cumple; el espacio global no es medible. De similitud en similitud se llega a la diferencia. Quitad al sujeto y sus representaciones (extraed el espacio de sus perspectivas visual y manual) y el espacio será no euclideano. Lo hacemos auclideano los hombres con nuestras visiones y nuestros manejos.

Arquímedes enunció así el principio métrico fundamental: si se transporta un número suficientemente grande de veces el segmento $A B$ sobre la recta, en algún momento será alcanzado el punto $\mathrm{C}$ - sobre la misma recta-, por alejado que esté de B. Evidente. Pues Veronese suprimió el axioma de Arquímedes y produjo una geometría no arquimedeana que violenta el sentido común. Sin embargo, la geometría de Veronese es la más adecuada para representaciones a nivel microfísico. Después de todo —oh gran Zenón- Aquiles no llegará a alcanzar a la tortuga.

\section{c.2.3) Continuidad y derivabilidad}

a) Para la intuición corriente, casi todas las curvas son continuas, casi todas las curvas continuas son derivables. De ahí la creencia de que - casitodo tiene sentido. Los caminos llevan a alguna parte.

Si partimos de la ecuación que describe el movimiento uniformemente acelerado:

$$
S=\alpha t^{2}
$$

La primera derivada ( $\alpha t)$ es la velocidad y la segunda derivada $(\alpha)$ es la aceleración; en cada punto podemos calcular las dos derivadas (el móvil conserva el impulso que le lleva a alguna parte determinada).

b) Pero, gracias a Thom ${ }^{23}$ y Mandelbrot ${ }^{24}$, hemos aprendido que la continuidad es una excepción en las curvas, que la derivabilidad es una excepción en las curvas continuas.

Podemos considerar espacios lisos y espacios estriados: isótropos y anisótropos, según que todas las direcciones y sentidos sean o no equiprobables,

23 René Tном, Modèles mathématiques de la morphogénèse, París, 10/18, número 887, 1977; Satabilité structurelle et morphogénèse, Inter Editions, 1977.

24 Benoít Mandelbrot, Les objets fractals, París, Flammarion, 1975. 
respectivamente ${ }^{25}$. Un espacio estriado es un espacio canalizado, hay un sistema de comunicaciones que obstruye algunas de las direcciones y sentidos.

Thom analiza la génesis de espacios estriados en un contexto liso. En todo proceso se producen discontinuidades - catástrofes-; son los puntos en los que se inscriben las mutaciones y las revoluciones. Las catástrofes acaban tomando forma; el orden es desbordado por el desorden, pero el desorden acaba siendo recuperado.

Mandelbrot analiza los espacios lisos: fractales (por fracturados y por tener un número fraccionario de dimensiones); las trayectorias lisas - movimientos brownianos- se representan por curvas continuas sin derivada. Si no hay derivada no hay sentido, ni en los cursos ni en los discursos; los caminos no llevan a ninguna parte, los móviles no llevan ningún impulso. La casi totalidad de los fenómenos reales (el perfil de una costa, la forma de un copo de nieve, un sistema de circulación - de aire, de sangre o de agua-) sólo son representables por curvas fractales; por ejemplo, la de van Koch representa un copo de nieve y una de sus aplicaciones puede representar el perfil de una costa; una aplicación arborescente a la curva de Peano produce una buena representación de los cursos del aire en los pulmones, de la sangre en su sistema circulatorio, del agua en una cuenca hidrográfica; la esponja de Sierpinski podría dar pie para una buena representación del universo.

c) Casi todos los procesos ordenados están atravesados por discontinuidades catastróficas, aunque la mayoría de las catástrofes acaben tomando forma.

Casi todos los procesos son desordenados: son caóticos. Podemos indicar una gradación de cuerpos: sólido (conserva la forma y el volumen), fluido (conserva, si líquido el volumen, si gas ni el volumen - pero sí la masa-), llama (no conserva nada) ${ }^{26}$. El sólido es un modelo de orden, el fluido es ordenable por una red de canales sólidos, la llama es un modelo de desorden. Pero es cuestión de espacio y tiempo; a escala muy pequeña y muy grande (quarks y galaxias) y a ritmo muy largo (haced una foto de un sólido cada cien añós y luego pasad la película) no hay más que llamas.

\section{Aspectos semánticos y pragmáticos de la medición}

"A tree is best measured when it is down."

(Proverbio norteamericano.)

Hasta ahora hemos dejado hablar al lenguaje de la medida, y al subconjunto del lenguaje que es el lenguaje matemático. Ese es el texto.

25 Gilles Deleuze y Félix Guattari, Capitalisme et schizophrénie: mille plateaux, Minuit, 1980 , págs. 592 ss.

26 Serres, op. cit., págs. 40 ss. 
Ahora vamos a retroceder -o avanzar - al contexto, al lenguaje común. En vez de dejar hablar a la medida vamos a hablar sobre ella. Vamos a tomarle medidas a la medida.

Junto al componente sintáctico se señalan — desde Morris- otros dos componentes, semántico y pragmático, en el lenguaje (y eso tanto en el lenguaje común como en el sublenguaje matemático) ${ }^{27}$. Semántica es lo que dice, pragmática en lo que hace. Los dos componentes son complementarios: hasta hace poco se manifestaba sobre todo el componente semántico, ahora se manifiesta sobre todo el componente pragmático.

Deleuze y Guattari ${ }^{28}$ diferencian una copia de un plano: la copia es una metáfora, el plano es - también- una metonimia (comprende un programa para manejar las cosas representadas). En la Galaxia Gutenberg predominaban las copias, en la Aldea Global predominan los planos. Algo tiene que ver esta situación con el hecho de que la memoria de la sociedad (que en las sociedades no escribientes se grababa en los cuerpos) se grabe, además de en los libros y sobre todo, en dispositivos electrónicos.

Un plano contiene un lugar para el que lo lee: para mirar el plano hay que situarse (estamos aquí: $O$ ). Una copia no contiene un lugar para el que la mira: el lugar del lector es exterior a la copia (es el lugar del que mira, desde fuera, la página). En el plano está representado el sujeto y en la copia no. En la Galaxia Gutenberg los libros sólo se comunicaban entre sí si alguien los leía: el lector era el conector entre los libros. En la Aldea Global los dispositivos electrónicos pueden comunicarse sin mediación de un lector (informatización de la sociedad): tienen sus propios conectores, y hay que buscarle al sujeto un lugar entre esos conectores (para que pueda operar).

El componente semántico de los lenguajes no era más que una coartada del componente pragmático ${ }^{29}$ : el lector era programado - por los libros- sin que se diese cuenta (la ideología cumplía esa función: sujetaba a los que se creían sujetos). Ahora, la ideología se ha reabsorbido: no hace falta, se va directamente al grano (a mandar) ${ }^{30}$.

27 En el lenguaje matemático, los componentes están desequilibrados: casi no hay semántica (lenguaje formal), casi todo es pragmática ("La forma primaria de comunicación matemática no es la descripción sino la inyunción -prescripción-": Spencer-Brown, op. cit., pág. 77).

28 Op. cit.

29 En realidad es algo más. En la medida en que hay una indeterminación del sujeto, el componente semántico mide lo que hay en él de sujeto ("saber para prever") y el componente pragmático mide lo que hay en él de sujetado ("prever para poder").

30 En una interesante novela de Thierry BREToN -informático francés- y Denis BENEICH [Softwar (la guerre douce), Laffon, 1984], la guerra energética deja paso a la guerra informática: el conflicto es de ideologías y de programas, y entre ideologías y programas (el antagonismo ideología/programa se plantea en la oposición externa entre bloques -URSS/USA-, pero también en las oposiciones internas a cada bloque -por ejemplo, Chernenko/Andropov en la URSS e ideólogos/tecnócratas en el Gobierno socialista francés). Los que dominan los programas acaban ganando: la política deja de estar en el puesto de mando. 
Un dispositivo de medida es un dispositivo de representación ( «sea un conjunto, produce un subconjunto que produce una ley que reproduce el conjunto»): el subconjunto es la unidad de medida que por iteración reproduce el conjunto, la ley dice que «no quede nada no medible» (que no quede resto del orden). Y esto es así, tanto en una dimensión semántica (la representación es una copia) como en una dimensión pragmática (la representación es un plano -un programa-: entonces, se llama reproducción).

La crítica de los dispositivos de medida se inscribe en la crítica de la representación: vamos a hacer esa crítica, primero en la perspectiva del saber, luego en la perspectiva del poder (las dos perspectivas son complementarias).

\section{a) Aspectos semánticos}

Un análisis de la representación nos lleva a plantear dos problemas:

- La relación entre lo global (universo) y lo local (lugar): entre el conjunto y el subconjunto que funciona como unidad de medida y ley de valor ${ }^{31}$.

- La naturaleza de lo local: pues es distinta, a distintos niveles (físico, vital, social), y - dentro de cada nivel- en distintos puntos y en distintos momentos.

\section{a.1) Lo local y lo global}

La razón clásica postulaba la posibilidad del paso de lo local a lo global: dadme la posición y el estado de movimiento de todas las partículas —decía Laplace - y tendré todo el saber/poder sobre el universo.

El cálculo infinitesimal parecía hacer realizable el proyecto: diferenciar para pasar de lo global a lo local, integrar para pasar de lo local a lo global. Este cálculo parecía completar la razón analítica: la totalidad de la curva se puede obtener a partir de un número finito de puntos (pero recordemos que la mayoría de las curvas no son continuas, que la mayoría de las curvas continuas no son derivables). Pero, aunque la diferenciación sea posible, la integración no es posible ${ }^{32}$.

La razón (la relación entre lo medido y la unidad de medida) no se conserva de lo local a lo global. Toda medida es local (y temporal), toda razón es local (y temporal).

31 En toda relación de dominación, la mayoría dominante funciona como ley de dominación (la unidad de medida es la ley de la medida): por eso, en la relación hombre/mujer, "hombre" designa a la vez a la mayoría dominante (los machos) y a la ley de dominación (el machismo como modelo de humanidad); por eso tienen el mismo nombre el macho humano y el ser humano genérico - "hombre" es macho, adulto y heterosexual; los niños, las mujeres y los homosexuales son llamados con otro nombre.

32 Serres, op. cit., pág. 89. 
El paso de lo local a lo global no es posible: ni en el espacio ni en el tiempo, ni dentro de una ciencia ni entre las ciencias.

$\mathrm{Ni}$ en el espacio ni en el tiempo. Newton dio el salto: de la caída de una manzana a la gravitación universal. Pero fue una casualidad, pues -como dice Serres ${ }^{33}$ - , «cayó dos veces sobre casos de armonía, cálculo y fenómeno». Esta situación se presenta muy pocas veces. El camino analítico es metódico, pero el método - y las técnicas - sólo funciona durante breve tiempo para breves espacios. El orden está sumergido en el caos, el universo cambia (el único universo es el universo de discurso). Lo local —dice el método- está incluido y se distribuye en lo global. Ambas suposiciones son falsas: no hay inclusión -nada es perfectamente continente- (pues hay cambio: los caminos están cortados por obstáculos - Thom - y se pienden en el caos - Mandelbrot-) ni distribución (hay estructuras a distintos niveles en el camino de lo global). Sólo es computable lo recursivo (Church) ${ }^{34}$. La computación de una parcela por pequeña que sea requerirá tanto tiempo y tanta energía - por lo menoscomo los que han sido necesarios para producirla (Brillouin). Aunque pudiéramos computar el universo, esta computación llevaría tanto tiempo que cuando la hubiéramos terminado el universo presente no se parecería nada al universo representado (Spencer-Brown).

No es posible en una ciencia (por tanto) ni entre las ciencias. No sólo son separables los objetos formales sino también - parcialmente- los objetos materiales. La realidad es cuasi-descomponible ${ }^{35}$ : la fuerza de las interacciones decrece y la velocidad de las transformaciones crece de un nivel a uno más alto de organización de la materia. Por eso son posibles las físicas, las biologías, las psicologías/sociologías. Es cuasi-descomponible, no totalmente descomponible: para manejar la parte que no es descomponible proliferan ahora los encuentros interdisciplinares y las perspectivas transdisciplinares. Además, la clasificación de las ciencias no obedece — sólo ni principalmente- a la lógica de descomponibilidad de lo real: las ciencias pertenecen al orden social y la relación entre ellas obedece a la lógica de ese orden. El saber se distribuye en escuelas y sectas, en grupos de presión y mandarinatos: sólo se busca el poder social (valor de cambio económico en forma de dinero y valor de cambio semántico en forma de prestigio). La organización del saber es un obstáculo epistemológico para el saber. Un paso — dentro de una ciencia, entre las ciencias - sólo lo produce una invención. Pero las invenciones no vienen de dentro (del método, no hay método de invención), vienen siempre de fuera

33 Op. cit., pág. 21.

34 Sólo se puede comprender lo que se puede comprimir: sean dos series, 01010101010101010101 y 01101100110111100010 , la primera se puede comprender porque se puede comprimir en "diez veces 01"; la segunda serie -aleatoria- no se puede comprender porque no se puede comprimir (según Chartis, "Randomness and mathematical proof", en Scientific American, 232/5, 1975).

35 Herbert A. STmon, "The organization of complex systems", en Howard H. Pattee, Hierarchy Theory: The Chalenge of Complex Systems, Doubleday, 1973 -en adelante citaremos PatTeE, 1973. 
(del ruido circundante: para inventar hay que absorber ruido). La integración del saber se produce por saltos — catástrofes-: y es imprevisible («el espíritu sopla donde quiere»).

Sólo subsiste un cuantificador universal: la historia. Podemos decir sin temor a equivocarnos: todo lo que existe es histórico (por eso hemos podido emplear aquí expresiones como «Toda medida es local»). Y nadie puede parar la historia, aunque el proyecto histórico de la burguesía haya sido pararla.

\section{a.2) Lo local social}

Regresemos de la perspectiva transdisciplinar a la perspectiva disciplinar de la sociología. ¿En qué medida los objetos con los que se enfrentan los sociólogos se prestan a la medición? La crítica más aguda ha sido la de Cicourel $^{36}$. Y tiene la ventaja de ser una crítica interna.

En relación a la solidez del nivel físico de realidad, el nivel social de realidad es muy fluido. Luego hablaremos de dos dispositivos de fluidificación que son los modelos de los dispositivos de medida: el dispositivo nominal de la lengua (que produce valor de cambio semántico: gaseoso) y el dispositivo numeral de la moneda (que produce valor de cambio económico: líquido).

Cicourel ${ }^{37}$ hace una reserva global y dos reservas locales a la introducción de la medida en ciencias sociales. La reserva global: sólo podemos medir magriitudes orientadas y por tanto para medir dentro del orden social tenemos que determinar qué sea el sentido - principio de orientación en ese orden (de ahí la importancia de los enfoques lingüístico y semiótico en la investigación social _- Las reservas locales: la primera, es el problema que plantean las proposiciones compuestas; la segunda, que es una generalización de la primera, es el problema de la equivalencia. Si decimos, por ejemplo, «delito», estamos en presencia de una proposición compuesta: pues designa un conjunto heterogéneo y complejo, en su extensión conjunto de los llamados delincuentes, en su comprensión conjunto de propiedades que definen al delincente (con arreglo a las leyes vigentes hoy en España, la figura del delincuente acoge a personajes tan variados como José María Ruiz Mateos, José Luis Pitarch, Jaime Milans de Bosch, el juez Varón Cobos, los envenenadores de la colza y cualquier chorizo anónimo; con arreglo a la legislación anterior, acogería a todos los ministros del Gobierno). Cuando estudiamos los órdenes físico o vital nos encontramos con cosas que existían antes de ser nombradas (la palabra ha venido después de la cosa): cuando estudiamos el orden social no encontramos otras cosas que palabras (el orden social está hecho de dictados e interdicciones, es del orden del decir). ¿Cómo es posible la equivalencia? Para que haya equivalencia han de darse: reflexividad, simetría y transitividad. Pero las

36 Aaron V. Cicourel, El método y la medida en sociología, Editora Nacional, 1982.

37 Op. cit., pág. 53. 
relaciones sociales no tienen esas propiedades: especialmente, «A=A»(A cambia en el espacio - al cambiar la escena social - y en el tiempo - al evolucionar- $)^{38}$; también $\sim[(A=B) \rightarrow(B=A)]$ —todos somos iguales pero algunos son más iguales que otros-; e incluso la trasitividad no se da siempre (especialmente cuando cambiamos de escenario: Pedro, Juan y Luis son iguales en la oficina pero en casa Luis es el padre de Juan). Lo mismo que decimos para las clases de equivalencia podíamos decir para las clases de orden.

Para matematizar el orden social hay que matematizar el lenguaje: conjugando la topología y la dinámica Thom ha hecho avances interesantes en este sentido ${ }^{39}$. Habría que cambiar no sólo las matemáticas sino también la lógica. En el orden de las relaciones sociales difícilmente son aplicables los principios de identidad, no contradicción y exclusión de tercero. Precisamente, porque a este nivel, la energía de interacción es débil y el ritmo de cambio es fuerte. De ahí la búsqueda de otras lógicas - polivalente-: en el límite la lógica del budismo zen. Dice el tetralema: es cierto que $A$, es cierto que no $A$, es cierto que $A$ y no $A$ y es cierto que ni $A$ ni no $A$. Por ejemplo: la organización social que mejor funciona es la que incluye jerarquía $(A)$, heterarquía $(B)$, poliarquía $(\mathrm{A} \text { y } \mathrm{B} \text { ) y anarquía (ni } \mathrm{A} \text { ni } \mathrm{B})^{40}$.

\section{a.3) La interpretación de las cifras}

La lógica que genera el orden social es más suave que la lógica que genera los órdenes físico y vital. De ahí que no podamos utilizar la misma lógica para dar razón de los distintos órdenes. Cuando demos con la lógica adecuada se producirá la misma armonía que se produjo con Newton.

Esta lógica ha de ser construida a partir de una reflexión sobre lo que constituye la expresión del orden social: el lenguaje y, en general, los dispositivos semióticos (significantes) ${ }^{41}$.

En el orden social hay fenómenos y procesos cuantificables en sentido estricto: por ejemplo, en demografía (que se refiere a las bases biológicas) y en ecología (que se refiere a las bases físicas). También son cuantificables fenómenos y procesos específicamente sociales: es posible la economía, en sus tres versiones de intercambio de objetos (economía política), intercambio de

38 Los objetos físicos - por ejemplo, un cristal- reciben toda la información de una vez. Los objetos vitales y sociales reciben a lo largo de su vida diferentes aportes de información: los seres vivos no humanos reciben de una vez el aporte principal de información - la información genética- (reciben, por aprendizaje, sólo un complemento de información que apenas se hereda por tradición cultural), los seres humanos socializados reciben gradualmente el aporte principal de información - la información lingüística- (el aprendizaje, que se hereda por tradición cultural, es más importante que la herencia). Los seres humanos socializados son más afectados por la historia.

39 Op. cit.

40 Edgar Morin, La Méthode. 2: La vie de la vie, Seuil, 1980, págs. 303 ss.

41 Jesús IBáñez, "Análisis sociológico de textos y discursos" (aparecerá en 1985 en Revista Internacional de Sociologia). 
sujetos (economía libidinal) e intercambio de mensajes (economía significante). $\mathrm{Y}$ son cuantificables porque los dispositivos de intercambio incluyen dispositivos de cuantificación o medida - dispositivos de valoración-: el dispositivo de la moneda produce la cuantificación de los bienes y servicios (extensiva, de razón), el dispositivo de la lengua produce la cuantificación de las significaciones (extensivo/intensiva, nominal u ordinal), el dispositivo de sexualidad produce la cuantificación de los objetos sexuales -intensiva-. No es un azar que el acceso al saber en ciencias sociales (la sociología académica está calculada para obstruir el saber y no para producirlo: para que los que están en el poder se reserven todo el azar) se haya producido desde una crítica de la economía política (Marx), desde una crítica de la economía libidinal (Freud), desde una crítica de la economía significante (Saussure): y que la articulación de esas rupturas parciales se vaya produciendo por cruces entre las respectivas aberturas (Lacan es el lugar de un cruce Freud/Saussure, Foucoult es el lugar de un cruce Marx/Freud, Serres es el lugar de un cruce Marx/Freud/ Saussure, etc.).

Los que no se plantean estos problemas - los meramente cuantitativoshacen cosas que no tienen sentido. Miden objetos que no tienen -o no tienen esas- propiedades de medida: por ejemplo, una escala interval de opinión (la opinión no tiene propiedades numéricas de nivel interval, todo lo más ordinal). Interpretan abusivamente las cifras obtenidas como resultado de esa medición: por ejemplo, calculan la opinión media de un conjunto compuesto (a nivel ordinal no se puede sumar ni multiplicar, a nivel interval no se puede multiplicar: para calcular una media hay que sumar y multiplicar).

La cuantificación suele ser una mera figura retórica (connota precisión pero no lo denota). Hay una figura retórica central: la sinécdoque ${ }^{42}$. La metáfora y la metonimia son combinaciones de sinécdoques. Cuando utilizamos datos cuantificados sin precisar el encaje con la teoría estamos en presencia de una sinécdoque. Cuando la correspondencia entre el lenguaje teórico de la sociología y el lenguaje matemático es sólo una vaga analogía estamos en presencia de una metáfora. Cuando la correspondencia vaga en el orden del pensamiento oculta una correspondencia no tan vaga en el orden de la acción estamos en presencia de una metonimia (es lo que vamos a ver ahora: lo que no tiene significado semántico puede tener sentido pragmático).

\section{b) Aspectos pragmáticos}

$\mathrm{Y}$, sin embargo, se mueve. Si abrimos cualquier libro o revista marcados con el membrete «sociología», empezarán a derramarse por el suelo los números que rebosan sus páginas. $\mathrm{Y}$ lo curioso es que, cuando intentemos leer esas páginas, apenas notaremos la ausencia de los números derramados.

42 Términos sugeridos por Garfinkel a Cicourel. 
¿Por qué lo hacen?: porque les pagan (en dinero y/o en prestigio: no, desde luego, en placer) por hacerlo. Pero, ¿por qué les pagan? Si en una perspectiva semántica no valen casi nada esos números, ¿valdrán algo en una perspectiva pragmática?

Ya Cicourel ${ }^{43}$ ponía en relación la cuantofrenia investigadora y la praxis burocrática: «No es casual — decía- que las medidas empleadas por los sociólogos tengan su utilización más intensa al aplicarse a los datos producidos por la burocracia moderna (...) lo que veneran los sociólogos como «datos» ${ }^{44}$ es, en su mayor parte, resultado de actividades organizadas burocráticamente, por ejemplo, la oficina del censo, la oficina de estadísticas demográficas o los organismos correccionales, de previsión o industriales» (y, podemos añadir, los dispositivos de producción de datos primarios imitan a estos dispositivos de producción de datos secundarios) ${ }^{45}$.

Desde Aristóteles, damos al término «información» dos sentidos: informarse de algo y dar forma a algo. Informatizar la sociedad es informarse de la sociedad y dar forma a la sociedad: informarse de la sociedad —informaciónpara dar forma a la sociedad - neguentropía-. Las cuantificaciones abusivas se sirven de la burocracia y sirven a la burocracia. El orden social es menos rígido - por más reflexivo- que otros órdenes: al emplear una lógica más rígida para informarnos de él damos forma a un orden más rígido.

Veamos, en un ejemplo, la correlación entre los niveles de medida y los niveles de constricción ${ }^{46}$. Al levantarnos, para curarnos de la libertad del sueño, tenemos que realizar ciertos ejercicios ascéticos de purificación: por ejemplo, mear, cagar, cepillarse los dientes, lavarse la cabeza, ducharse (eliminar las impurezas: los residuos de azar o ruido en el orden).

- Si no hubiese medida o constricción cada uno realizaría sólo las operaciones que le apetecieran - principio del placer-.

- A un nivel nominal de medida o constricción las operaciones obligatorias serían nominadas: pero cada uno podría realizarlas en cualquier orden $y$ demorarse en ellas o entre ellas a placer.

43 Op. cit., pág. 65 .

44 Los datos no se recogen, se producen. Como sugiere LaING (The politics of experience and the bird of paradise, Penguin Books 1967, págs. 52 ss.), más que hablar de "data" habría que hablar de "capta". Efectivamente, la investigación es una extensión de la caza ("uestigo" es seguir las huellas de la presa): el sistema de ejes de coordenadas de Descartes es la estilización de un dispositivo de caza: el cazador se agazapa en el punto $O$ (origen), la presa se condensa en el punto $\mathrm{P}(x, y), x$ e $y$ son los brazos del cazador -las pinzas para capturar la presa- (según Thom, Stabilité...).

45 Resulta inquietante el paralelismo entre la lista que da Cicourel y la lista de instituciones represivas, a través de las cuales el poder se capilariza, que ha ido analizando a lo largo de su vida Foucault.

46 El ejemplo no ha sido elegido a la ligera: el sujeto se socializa en la fase anal (el vínculo se desplaza del amor al temor). Tampoco han sido elegidos a la ligera los nombres de las operaciones: los términos "cagar" y "mear" no son habituales en el discurso académico (la provocación que implica su uso es un intento de sacar al lector de la clausura de ese discurso). 
- A un nivel ordinal de medida o constricción sería dictado ya el orden de realización, aunque quedaría libre el tiempo.

- Impuesto o dictado el orden, se pueden imponer o no, dictar o no, el origen (momento en que comienza la serie de operaciones) y la unidad (duración de cada operación).

- A un nivel interval de medida o constricción, aún son libres el comienzo y la duración absoluta, pero queda ligada la duración relativa (la razón entre las duraciones: invertirás en cagar dos veces lo que has invertido en mear, etc.).

- A un nivel de razón de medida o constricción queda ligado el comienzo - suena el primer toque de corneta- aunque sea libre la duración (aunque no las razones de duración).

- A un nivel absoluto de medida o constricción queda ligada también la duración: todas las operaciones se hacen a toque de corneta, el recluta ha perdido toda su reflexividad (el orden es absolutamente rígido).

Descendiendo por la escala de los niveles de medida o constricción hemos pasado del boudoir de Sade al cuartel. Salgamos raudo.

Pero no sin aprovechar la estancia en el cuartel para hacer una observación de pasada. La operación más elemental de medida es la clasificación, y clasificación viene de «classis» (= cuerpo de ejército). Toda operación de medida -que se informa de algo para informarlo- es militar. Sólo por la violencia puede imponerse la simplificación que la medición supone. No es extraño que, de medida en medida, hayamos ido a parar a un cuartel.

\section{QUIEN PUEDE MEDIR: TIPOS DE MEDIDORES}

"El mundo es como es: solamente un observador puede simplificarlo."

(Howard H. Pattee.)

"Todo lo dicho es dicho por alguien."

(Humberto Maturana y Francisco Varela.)

La medición es una operación subjetiva: más aún, es la marca de la subjetividad. No hay medición si no hay un sujeto que mide. El mundo medido es el mundo visto y manejado desde la perspectiva de un sujeto. No es posible una medición objetiva.

No hay mediciones físicas. Decía Galileo que el libro de la naturaleza está escrito en caracteres matemáticos. No es cierto. Las leyes naturales (físicas) son necesarias, y por eso no hay que escribirlas. No hay otras leyes escritas que las culturales (culturales vitales — nivel al que la ley está presente- y cul- 
turales sociales - nivel al que la ley está representada-). Sólo se escribe lo contingente: un código es un azar congelado (que se conserva). Un código es un dispositivo de clasificación y medida: lo mismo los códigos genéticos a rivel vital que los códigos lingüísticos a nivel social. Si hay códigos es porque han sido escritos, y si han sido escritos es porque han sido escritos por alguien (todo lo dicho es dicho por alguien). Si hay códigos es porque algo ha sido codificado (clasificado y medido). Si hablamos de alguien que escribe o codifica algo, nos hemos salido del orden físico: en el mundo físico no hay ni alguien ni algo, sólo hay todo (no se puede parcelar el todo porque no hay nadie que lo parcele). Los álguienes, y por tanto los algos, aparecen en el orden vital y se desarrollan en el orden social. No hay mediciones físicas: hay mediciones sociales (y vitales) del mundo físico.

A nivel vital, las leyes están presentes (los animales hacen), a nivel social están representadas (los seres humanos saben —o pueden saber- lo que hacen). Pero a nivel vital las cosas son representadas por las leyes presentes. Recordemos qué es una representación: un conjunto produce un subconjunto que produce una ley que reproduce el conjunto. Dice un biólogo: «Los organismos se enfrentan con el problema de replicación de niveles más altos de orden por replicación de las informaciones a niveles relativamente bajos de orden y luego por traducción y transformación sucesivas de esa información para generar niveles más altos de orden» ${ }^{47}$. Y esto ocurre, tanto en la operación metabólica --producción de sí- como en la operación reproductora -reproducción de sí-: por la primera operación, el organismo se construye a sí mismo; por la segunda operación, el organismo construye otro organismo a imagen de sí mismo (se reconstruye a sí mismo). Producción: un conjunto (organismo) produce un subconjunto (dispositivo enzimático) que produce una ley (metabolismo: producción de proteínas) que reproduce el conjunto (las proteínas forman parte del organismo). Reproducción: un conjunto (especie) produce en subconjunto (genoma) que produce una ley (transmisión del genoma a los descendientes) que reproduce el conjunto (los descendientes son miembros de la especie).

Vamos a ver la diferencia entre las leyes físicas y las leyes vitales y sociales. La diferencia es, precisamente, la introducción de procesos de clasificación y medida (necesarios para las representaciones implicadas en la producción y en la reproducción de sí). En el orden físico sólo hay acontecimientos: en los órdenes vital y social hay también registros (por códigos) de esos acontecimientos. En el orden vital registros de los acontecimientos (códigos genéticos), en el orden social registros de los registros de los acontecimientos (códigos lingǘísticos). El registro de los acontecimientos transforma el tiempo reversible de la física en los tiempos irreversibles de la biología y la sociología: pues el registro tiene que ser posterior al acontecimiento. El orden físico conoce una irreversibilidad: la irreversibilidad termodinámica que conduce a estados cada

47 Clifford Grobstein, "Hierarchical order and neogenesis", en Pattee, 1973. 
vez menos ordenados. Los dispositivos de registro (clasificación y medición) permiten invertir la flecha del tiempo: de la flecha termodinámica a la flecha histórica, de la entropía decreciente a la neguentropía creciente. La historia de los animales y las especies es una historia de la primera especie (hay registros sucesivos: hay historia). La historia de los individuos y las sociedades humanos es una historia de la segunda especie (hay registros de registros sucesivos: hay historia de la historia). El paso del orden físico al orden vital y el paso del orden vital al orden social son paradójicos. Esos pasos implican la introducción de la reflexión: una reflexión de la primera especie para el orden vital (reflexión de sí) y una reflexión de la segunda especie para el orden social (reflexión de la reflexión de sí). Para que el organismo viviente se produzca y se reproduzca, ha de ser capaz de reflexionar sobre sí mismo. Para que el organismo pensante vea y maneje este proceso de producción y reproducción de sí ha de ser capaz de reflexionar sobre la producción y reproducción de sí. Porque estos pasos implican la reflexión son paradójicos: para darlos hay que solucionar ecuaciones lógicas de grado par (segundo y cuarto, respectivamente), y en esas ecuaciones $x$ es función de $x$.

A menudo se ha hablado de la paradoja de la libertad: mi comportamiento es libre, el comportamiento del otro está determinado (por eso existen psicologías y sociologías). En el orden físico, cuando a un sistema se le han asignado las condiciones iniciales en un instante del tiempo sus estados pasados y sus estados futuros (indistinguibles, pues las leyes físicas son reversibles con relación al tiempo) quedan determinados, toda información suplementaria sobre estados pasados o futuros es o redundante o contradictoria ${ }^{48}$. ¿Cómo es posible, entonces, que pueda emerger del orden físico un sujeto u observador capaz de ver el pasado y de manejar el futuro? Ese sujeto es un sujeto/sujetado ( $y$ es sujeto en la medida - si está sujetado en una justa medida- en que está sujetado): esta condición de sujeto/sujetado es paradójica.

Es necesario que sea sujeto (que se despegue de las condiciones físicas) y es imposible que sea sujeto (pues está pegado a las condiciones físicas: sólo puede despegarse, como el barón de Münchausen, tirándose de los pelos). Cuando algo es a la vez necesario e imposible, hay que cambiar las reglas del juego. Esta paradoja se resuelve - la resuelve el proceso de la evolución, no sabemos muy bien cómo- mediante la invención de estructuras simbólicas junto a las estructuras físicas: mediante la invención de «lenguajes» (el protolenguaje hecho de códigos genéticos y el lenguaje hecho de códigos lingüísti$\cos )$. Una estructura simbólica es una estructura física que funciona como código. Como ejemplos extremos de estructuras física y simbólica: el hardware y el software de un ordenador (no llevemos muy lejos la analogía pues el ordenador es una máquina construída por los hombres y que los incluye

48 Howard H. Patter, "Las bases físicas de la codificación y fidelidad en la evolución biológica" (pág. 90), "El problema de la jerarquía biológica" (pág. 546), ambos en C. H. Waddington, Hacia una biología teórica, Alianza, 1976. En adelante citaremos estos artículos: Patter (1976 a) y Pattee (1976 b), respectivamente. 
como operadores). El bardware es la estructura física y el software es la descripción simbólica: el software es una descripción alternativa del hardware. Para manejar el software no hace falta conocer el hardware: lo mismo que un organismo puede comer y reproducirse, que un organismo pensante puede pensar, sin saber nada de anatomía ni de fisiología (veremos que, en ambos casos, es condición necesaria que no sepa — que olvide selectivamente muchos detalles-). A nivel físico, las estructuras no incluyen ninguna descripción (sólo hay hardware): podemos llamar «naturaleza» a una estructura aislada de sus descripciones. A nivel simbólico, las descripciones no incluyen ninguna estructra (sólo hay software): podemos llamar «cultura» a una descripción aislada de sus estructuras. El mecanismo del ordenador ha sido construído de modo que se pueda manejar el hardware (estructura) desde el software (descripción simplificada): en el otro extremo tenemos un sistema planetario qe es completamente incontrolable (la ley de la gravitación no altera para nada la gravitación: permite predecir, pero no controlar). De un lado un mecanismo sobre el que no tenemos control descriptivo (la descripción no influye en él), de otro lado un mecanismo sobre el que tenemos control descriptivo. La descripción es un reflejo de la estructura: el ordenador (que no ha aparecido espontáneamente: es producto de una reflexión de la segunda especie) es, como el cerebro humano (que ha aparecido espontáneamente), paradójico. Son paradójicas las relaciones entre estructura física y descripción simbólica: entre bardware y software. Porque para que haya una descripción alternativa tiene que haber detrás un sujeto. Una estructura física se hace, al menos en los límites micro y macro, indeterminada al intentar observarla: a nivel microfísico el observador perturba la estructura al describirla (principio de indeterminación de Heisenberg), a nivel macrofísico la descripción del observador es perturbada por la estructura al describirla (principio de relatividad de Einstein) ${ }^{49}$. Un sistema lógico suficientemente potente para incluir reflexividad o autorreferencia es incompleto - incluye proposiciones indecidibles- (principio de incompletitud de Gödel). Siempre la misma paradoja: medir la materia con instrumentos hechos de materia, medir el pensamiento con el pensamiento: ni la verdad teórica ni la verdad empírica son posibles. Las estructuras físicas son predecibles pero no son controlables: al intentar predecirlas se vuelven indeterminadas. Las descripciones simbólicas son controlables pero incompletas ${ }^{50} . \ll \mathrm{El}$ mundo es indudablemente sí mismo (esto es, indistinto de sí mismo), pero, en cualquier intento de hacer de él un objeto, debe, igual de indudablemente, actuar de modo que se haga distinto de sí mismo, y, por eso, falso a sí mismo» ${ }^{51}$. Conocer no es verificar sino, al menos parcialmente, falsear.

49 Los sociólogos se encuentran en estas condiciones: al observarla, perturban la realidad social (una sociedad en la medida en que se conoce -en que se mide a sí misma- cambia), y la realidad los perturba (sus observaciones son perturbadas por restricciones sociales).

50 Pattee, 1973, págs. 140-141.

51 SPENCER-Brown, op. cit., pág. 105. 
Para hablar de un sujeto podemos utilizar dos lenguajes. El primero: el de la presencia, el sujeto opera momento a momento como sistema determinado con clausura operacional. El segundo: el de la representación, el sujeto opera obteniendo información del medio para construir una representación de él (un mapa o plano: hay una doble diferencia, temporal y espacial, de la acción del sujeto). La primera es una descripción en-sí de la operación del sujeto (su dinámica interna), la segunda es una descripción para-sí de la operación del sujeto (su dinámica externa: sus interacciones con el medio). La primera es una descripción desde dentro, la segunda es una descripción desde fuera, del sujeto ( se le ve y/o se le maneja como un objeto, o él mismo se ve y se maneja como un abjeto - por una reflexividad de la segunda especie-). Maturana y Varela ponen el siguiente ejemplo: «Imaginemos a un sujeto que ha vivido toda su vida en un submarino y que, no habiendo jamás salido de él, ha recibido un entrenamiento perfecto de cómo manejarlo. Ahora nosotros estamos en la playa y vemos que el submarino se acerca y emerge grácilmente a la superficie. Entonces, tomamos la radio y decimos al piloto al interior: «Felicitaciones, has evitado los escollos y emergido con gran elegancia; las maniobras del submarino te resultaron perfectas». Nuestro amigo al interior, sin embargo, se desconcierta: «¿Qué es eso de escollos y de emerger? Todo lo que yo hice fue mover palancas y girar perillas y establecer ciertas relaciones entre indicadores al accionar las palancas y las perillas, en una secuencia prescrita de acuerdo a mi modo acostumbrado. Yo no he realizado maniobra alguna, y que, además, me hables de un submarino, me parece casi una burla» 52 .

La perspectiva del submarinista extraído del medio es causal y necesaria (es la perspectiva del bardware). La perspectiva del submarinista sumergido en el medio - perspectiva del observador del submarinista- es final y contingente (es la perspectiva del software). Causa y fin, necesidad y contingencia, son conceptos complementarios: según miremos hacia atrás y hacia dentro o hacia adelante y hacia fuera. Hay causas y necesidad si consideramos los registros como acontecimientos. Hay fines y contingencia si consideramos los registros como registros — como «mensajes»- ${ }^{53}$.

Hablaremos desde ahora el lenguaje del software: la perspectiva de la sociología es una perspectiva de software, no construye organismos ni cerebros sino que los maneja (la perspectiva del ingeniero genético o mecánico sería la del hardware).

52 Humberto Maturana y Francisco Varela, "Las bases biológicas del entendimiento humano. El árbol del conocimiento", Behncke, Maturana y Varela (Santiago de Chile), 1984 , pág. 91.

$53 \mathrm{El}$ sociólogo meramente cuantitativo es como el submarinista: puede hacer las cosas si está bien entrenado (pero es preciso que alguien le entrene). El sociólogo cualitativo es como el observador en la playa -como el submarinista si fuera capaz de desdoblarse, de reflexionar, de asumir imaginariamente la perspectiva del observador en la playa- (se puede entrenar a sí mismo). 


\section{Dispositivos de medida}

Un dispositivo de medida es un dispositivo doblemente articulado manejado por alguien ${ }^{54}$. En un dispositivo de doble articulación, hay una segunda articulación que elige en los flujos-partículas unidades moleculares metaestables a las que impone un orden estadístico de conexiones y sucesiones, $\mathrm{y}$ hay una primera articulación que construye estructuras estables, compactas y funcionales y las combina en compuestos molares.

Hay dispositivos de doble articulación a todos los niveles de organización de la materia. Por ejemplo: a nivel geológico, la segunda articulación sería la sedimentación y la primera el plegamiento; a nivel vital, la segunda articulación sería la formación de pequeñas moléculas y la primera la formación de macromoléculas ( $\mathrm{y}$, a otros niveles dentro de este nivel, proteínas/ácidos nucleos, o -dentro de las proteínas- proteínas lineales/plegadas y -dentro de los ácidos nucleicos - primera cadena/cadena replicada de los ácidos nucleicos); a nivel social, la segunda articulación sería la formación de fonemas ( sentido) y la primera la formación de monemas (con sentido).

Pero hay una profunda diferencia entre los dispositivos de doble articulación a nivel físico - estructurales - y a niveles vital y social — funcionales-. A los niveles vital y social hay un control jerárquico de la primera articulación sobre la segunda: este control jerárquico hace posible que el sistema, en vez de congelarse, evolucione. A nivel vital hay protosujetos, a nivel social hay sujetos: a nivel físico el único sujeto es la totalidad del universo.

Hemos visto que la realidad es cuasi-descomponible en niveles (físico, vital, social): pero también es descomponible en sub-niveles dentro de cada nivel. A nivel físico hay la escala átomo, molécula, cristal, sólido..., universo: hay diferencias en número (colecciones de menos a más elementos), en fuerza (interacciones de más a menos intensidad) y en tiempo (tiempos de más a menos largos). Esta es una jerarquía estructural: como la realidad es cuasidescomponible, podemos describir separadamente cada nivel asumiendo la hipótesis de que la colección es equivalente a una partícula típica representativa de la colección y las hipótesis de que el nivel inferior está promediado y que el nivel superior es constante (es lo que hacen, abusivamente, los sociólogos meramente cuantitativos: tratan a las jerarquías sociales -que son funcionales- como meramente estructurales). A nivel vital hay la escala macromoléculas, células, organismos, especies..., biosfera. A nivel social hay la escala individuos, grupos, grupos de grupos (familia, entidad de población..., nación...), ..., sociedad. Pero a estos niveles la jerarquía es funcional: el nivel superior controla la dinámica de elementos individuales o unidades singulares del nivel inferior (por lo que no se puede promediar ese nivel: un ácido nucleico o un jefe son singularidades no promediables). A estos niveles han surgi-

54 Paradigma construido por Delevze y Guattari, op. cit., págs. 55 ss. (cruzando ideas de Martinet y Hjelmslev). 
do protosujetos y sujetos. La colección de unidades constriñe el movimiento de unidades singulares: la constricción no es meramente distributiva (como lo es la constricción que las paredes de un balón ejercen sobre las moléculas del gas encerrado), sino que es estructural (como lo es la constricción que un grupo ejerce sobre los individuos que lo componen: no podemos clasificar el grupo en individuos, pues la unidad grupo es pertinente ${ }^{55}$. Por eso, para analizar a niveles vital y social tenemos que tener en cuenta al mismo tiempo por los menos dos niveles: lo pertinente son las condiciones de frontera -interfase o interfaz entre los dos niveles-. Tener nn cuenta el dispositivo completo de doble articulación ${ }^{56}$.

El control jerárquico implica una descripción alternativa del nivel inferior desde el nivel superior: una autoridad en el nivel superior (ácido nucleico o jefe) se erige en observador — se pone a distancia de las leyes físicas - y desde su altura describe alternativamente el sistema: sustituye la descripción dinámica por una descripción estadística, una descripción que no influye por una descripción que influye. La descripción dinámica es reversible en el tiempo, la descripción estadística — pues se basa en una clasificación o medida - es irreversible en el tiempo (la descripción dinámica no es en realidad una descripción pues es redundante a la estructura). La descripción alternativa, para que tenga sentido o valor de supervivencia (esto es, para que las clasificaciones y/o mediciones tengan sentido), ha de cumplir dos condiciones: que realice una simplificación óptima, y que opere con clausura estadística.

La clasificación y la medida implican simplificación: para que los elementos puedan ser agrupados en clases, han de ser borradas ciertas singularidades (hay que distinguir los detalles significativos de los no significativos). Hay un nivel óptimo de simplificación: por ejemplo, para controlar el tráfico, un código de señales funciona mejor si incluye una medida de la intensidad del tráfico y liga el tiempo de encendido de las luces a esa medida, pero no funciona mejor porque cuente el número de pasajeros de los automóviles (el primero es un detalle significativo, el segundo es un detalle insignificante - a los efectos del tráfico-). La mayor parte de las mediciones que realizan los sociólogos son de detalles insignificantes: hay una confusión del rigor con la minucia. Si se incluyen todos los detalles en la clasificación ya no hay clasificación (hemos regresado al mundo físico).

El éxito en un proceso dinámico depende de la asignación precisa de las condiciones iniciales: en el lanzamiento de un proyectil, posición y velocidad del móvil y del blanco. El éxito en un proceso estadístico es independiente de las condiciones iniciales: en una reacción química se produce el equilibrio

55 Se discute si un ejército se democrático: hay dos definiciones, una distributiva (todos o la mayoria de los militares son demócratas), otra estructural (las relaciones entre los militares son democráticas y el ejército se utiliza para fines democráticos).

56 Pattee, 1973, págs. $76 \mathrm{ss.}$ 
sean cualesquiera las condiciones iniciales. En el primer caso, un error inicial lleva al caos. En el segundo caso, el caos inicial lleva al acierto. A nivel social: una dictadura imita al sistema dinámico, la anarquía imita al sistema estadístico. El control jerárquico - y la organización social no dictatorial ni anárquica- combina los dos tipos de procesos. Es operado por una colección de elementos (es estadístico) pero opera sobre la dinámica de elementos singulares (es dinámico). Pattee ${ }^{57}$ llama a esta combinación clausura estadística: se habla de clausura matemática cuando una operación con elementos de un conjunto produce otro elemento del conjunto - la ampliación del campo de los números es una carrera en pos de la clausura matemática-, hay clausura estadística cuando una colección de elementos persiste en virtud de los gradientes de combinaciones entre esos elementos (clausura porque la colección persiste, estadística porque depende de gradientes o concentraciones - tasas-). Ejemplos: a nivel vital, la selección natural opera en virtud de una constricción colectiva que limita la estructura detallada de cada elemento dentro de un conjunto estadísticamente cerrado (especie); a nivel social, el grupo es una colección de individuos que modifica a cada individuo - haciéndoles asumir papeles que no son función de características individuales distribuídas, sino de características colectivas no distribuidas (estructurales) - manteniéndoles dentro de la colección (dentro de los límites del grupo). El ácido nucleico y el jefe son singularidades, por decirlo así, estructurales. Son conjuntos estructurales: las singularidades de ellos, como elemento, apenas cuentan (no se ocupa el poder, se es ocupado por el poder).

Cuando se clasifica o se mide se reemplazan los detalles microscópicos por alguna media (la clase «individuo humano» hace abstracción de las singularidades individuales, pero esta clase es necesaria para poder contar personas ${ }^{\circ}$ — cada persona es una media o individuo típico-): esto es la clasificación alternativa. La autoridad es un control del azar (reservarse el azar y atribuir la norma): promedia a los individuos.

Se plantean dos problemas: cómo funcionan estos dispositivos y cómo han surgido estos dispositivos. Las dos preguntas son complementarias: desde el nivel superior de una jerarquía se dan por supuestas las ligaduras o constricciones y el problema es cómo funciona (es la perspectiva de los sociólogos distributivos o cuantitativos), desde el nivel inferior de una jerarquía son las leyes de movimiento las que se dan por supuestas y el problema es cómo ha surgido la ligadura -que limita los movimientos físicamente posibles- (es la perspectiva de los sociólogos estructurales o cualitativos) ${ }^{58}$. Se utilizan, un concepto clásico de medida en la primera perspectiva, un concepto cuántico de medida en la segunda perspectiva.

El concepto clásico aparece en relación con las ligaduras. Este concepto aparece en física como tratamiento de algunos grados de libertad como estados

57 1973, pág. 94.

58 Pattee, 1976 a, pág. 94. 
geométricos que no dependen del tiempo ni de las leyes de movimiento. Es el caso del cristal: al principio del proceso de cristalización hay tantos grados de libertad como moléculas, pero a medida que la solución cristaliza los grados de libertad para las moléculas no cristalizadas van decreciendo (hay partes del espacio ocupados por la materia cristalizada). Estas ligaduras holónomas o integrables llevan a la congelación o crịstalización del sistema: los grados de libertad se van reduciendo hasta no quedar ninguno. El cristal no tiene que realizar clasificaciones y medidas porque no tiene alternativas: el proceso de cristalización sólo tiene un camino. Es el caso, también, de una organización burocrática (y del tipo especial de organización burocrática que es la institución académica). Las ligaduras no holónomas o no integrables no llevan a la congelación sino a la flexibilidad del sistema: las ligaduras holónomas generan un orden rígido, las ligaduras no holónomas generan un orden flexible. Una ligadura no holónoma o no integrable lleva a un sistema a un número de grados de libertad intermedio entre la «anarquía» (caos termodinámico) y la «dictadura» (orden dinámico). En una dictadura sólo hay dictados e interdicciones, sólo hay constricciones (está prohibido todo lo que no es obligatorio). La dictadura persigue un nivel de solidez y cristalización análogos a los de los estratos físicos. Todo está determinado: hay una aplicación uno-a-uno (biunívoca). En una organización no anárquica y no dictatorial algo está determinado y algo no está determinado: hay una aplicación uno-a-varios (de ahí la necesidad de clasificar las alternativas —esos varios para cada uno-). Si hay ligadura no holónoma debe haber más grados de libertad en la descripción estática que en el funcionamiento dinámico del sistema. Volvemos a la paradoja: ¿cómo es posible explicar mediante las leyes de movimiento - físicasalgo que modifica esas leyes de movimiento?, ¿cómo aparecen el el orden físico dispositivos metafísicos?

La mecánica estadística (cuántica) se plantea desde la interfase entre los dos niveles: ya el nombre lo dice, «mecánica» (referencia a procesos dinámicos) «estadística» (referencia a procesos estadísticos). Una medida mecánicocuántica procede así: las ecuaciones cuánticas de movimiento se interpretan como amplitudes inobservables de probabilidad (ondas), bajo ciertas condiciones estas amplitudes de probabilidad pueden correlacionarse con variables observables en el mundo clásico; las ecuaciones cuánticas de movimiento son reversibles en el tiempo y realizan una transformación biunívoca de las funciones de onda, por lo que ha de realizarse una segunda transformación (reducción de las funciones de onda), que es un proceso irreversible que implica una clasificación alternativa o transformación no biunívoca ${ }^{59}$. No se colma el abismo entre procesos dinámicos y estadísticos: cuanto más precisos se hacen los formalismos mayor es la ignorancia de los detalles (la ignorancia de los detalles es necesaria para realizar una medición y la ignorancia de los detalles de la medición es necesaria para realizar una medición de la medición). Un disposi-

59 Pattee, 1976 a, pág. 98. 
tivo clásico de medida es exterior (construido por los seres humanos -en el nivel social-) y de gran tamaño (por ése se distinguen el dispositivo de medida y lo medido con él). La medida cuántica que hemos descrito es la que realizan los físicos. Pero los físicos imitan procesos de medida que han surgido espontáneamente: las mediciones que se realizan en el orden social son un desarrollo de las mediciones que se realizan en el orden vital. El dispositivo más elemental de medida que se conoce es el dispositivo enzimático. Un enzima es una cadena monomérica (enlaces de la misma molécula) o polimérica (enlace en una secuencia ordenada de distintas moléculas) que, cuando alcanza cierta extensión, se pliega. Sólo plegada alcanza la capacidad de medir. Los enlaces fijos que mantienen plegada la cadena son débiles, los enlaces que el enzima cataliza son fuertes. El enzima opera una clasificación de las alternativas mediante la catálisis de esos enlaces fuertes, controlando unos pocos grados de libertad gracias a las interacciones de numerosos grados de libertad. Un enzima ( $y$ en general una máquina cuántica) se desintegra antes de funcionar mal: esto es así porque los enlaces dentro del enzima son débiles (no los enlaces de secuencia pero sí los enlaces de conformación) y los enlaces que cataliza el enzima son fuertes: si, por ejemplo, se calienta pierde su capacidad catalizadora al perder su conformación (se desintegra antes de funcionar mal). Un reloj ( $\mathrm{y}$ en general una máquina clásica) funciona mal antes de desintegrarse: los enlaces de conformación son fuertes y los enlaces de funcionamiento son débiles ${ }^{60}$. El investigador social funciona dentro del orden social como el enzima funciona dentro del orden vital: puede funcionar como máquina clásica (como algoritmo o robot) si sus enlaces de conformación son fuertes (por ejemplo, la rigidez de sus ideas y métodos) y sus enlaces de funcionamiento son débiles (por ejemplo: se pliega a las presiones de los poderes constituidos); puede funcionar como una máquina cuántica si sus enlaces de conformación son débiles (por ejemplo, la flaxibilidad de sus ideas y métodos) y sus enlaces de funcionamiento son fuertes (por ejemplo: su pensamiento resiste a las presiones de los poderes constituídos). El enzima es una condición de frontera, distinta de la condición de frontera que es, por ejemplo, un balón, en el sentido en que el enzima es interior y el balón exterior al sistema cuyos grados de libertad restringen (el enzima ha emergido espontáneamente y está al servicio del sistema -clausura estadística-). El investigador social es también una condición de frontera: es un producto espontáneo del sistema social que está al servicio del sistema social. Es condición de funcionamiento de la máquina social —a partir de cierto momento de su evolución, cuando alcanza un nivel de reflexividad de la segunda especie, cuando la sociedad se hace consciente de sí misma de modo que puede funcionar y saber cómo funciona-: y es condición de funcionamiento en la medida en que resiste a las presiones de esa máquina social ( $o$ en cuanto transforma esas presiones en un sentido que tenga valor de supervivencia para el sistema). Los sistemas vitales son complejos (reflexi-

60 Pattee, 1976 a y 196 b. 
vos: hay reflexiones de la primera especie). Los sistemas sociales son hipercomplejos (sistemas reflexivos - sociedades- que incluyen componentes reflexivos -individuos-: operan una reflexión de la segunda especie, cuando la sociedad se piensa a través de sus pensadores). Para describir un proceso de medida cuántica, como el que realizan el enzima o el investigador cualitativo, son necesarias dos escalas de tiempo: con tiempos de relajación muy diferentes, relajación lenta de los enlaces fuertes y relajación rápida de los enlaces débiles. Una de las dos escalas debe describir un proceso irreversible. En los dispositivos de medida clásica no se tiene en cuenta la escala con tiempo de relajación lento: se considera como dispositivo fijo. La escala es descartada del proceso dinámico y reemplazada por una estructura geométrica. Es lo que pasa cuando, en la investigación social, el sujeto-en-proceso es reemplazado por un algoritmo o robot (que sigue una metodología rígida).

La diferencia entre las medidas clásica y cuántica está en la consideración del dispositivo de medida como, respectivamente, exterior o interior al sistema. A niveles microfísico y social la distinción entre el dispositivo de medida y lo medido no es fácil (relación de indeterminación o incertidmbre). Si se considera el sistema entero - incluído el dispositivo de medida - no se reconocerá ninguna medida (es la perspectiva del submarinista). Si se considera sólo parte del sistema —excluído el dispositivo de medida - no se reconocerá ningún proceso (es la perspectiva del observador del submarinista). Los investigadores cualitativos proceden del primer modo, los investigadores cuantitativos proceden del segundo modo.

Queda planteado - para los investigadores cualitativos- el problema del origen: cómo emerge -en el orden físico - la vida, cómo emerge —en el orden vital - el pensamiento (cómo emergen el sentido del no sentido y el sentido del sentido del sentido: cómo emerge la asimetría en un mundo simétrico). Sabemos que estos potenciales de reflexividad - la aparición en el mundo de espejos y de espejos de espejos- es función de la complejidad: pero ignoramos las bases físicas de la autorreferencia. Sólo una molécula muy compleja pudo dar origen a la vida, sólo un organismo my complejo pudo dar origen al pensamiento. El problema del origen es un problema de límites: no sabemos lo que hay más allá del origen y lo que hay más allá del fin. Comprendemos la estructura de las primeras articulaciones, pero no comprendemos la génesis de las segundas articulaciones. ¿Qué es eso de que «elige en los flujos-partículas unidades moleculares metaestables a las que impone un orden estadístico de conexiones y sucesiones" —quién elige-? ¿Cómo han aparecido los protosujetos que utilizan, sin tener conciencia de ellos, dispositivos elementales de clasificación y medida y cómo se han desarrollado, a partir de ellos, los sujetos que sí tienen conciencia —o pueden llegar a tenerla si se ponen a pensar en ello- de cómo utilizan dispositivos complejos de clasificación y medida? El primer paso debe de haber sido más o menos así: por 
presiones estadísticas del entorno ciertas moléculas alcanzan una situación metaestable en términos de estados estacionarios de sistemas mecánicos cuánticos, y esas estructuras metaestables se han conservado durante tiempos de relajación variables ${ }^{61}$. Los pasos sucesivos han sido realizados por entidades a los que Simondon llama individuos: un individuo es una condición de frontera que divide el espacio-tiempo en dos sectores, un interior/pasado (lo ya integrado) y un exterior/futuro (lo aún por integrar). La escala de los individuos va del cristal a la célula y al organismo/especie y a la sociedad. El paso de un nivel a otro más alto de individualidad implica aportes suplementarios de información. El cristal recibe toda la información de una vez y la aplica reiterativamente a la conformación del medio (los investigadores cuantitativos se parecen en eso a los cristales). Cuando el cristal se transforma en organismo vivo -cristal asimétrico- desarrolla, por algún defecto o falla estructral, la capacidad de recibir sucesivos aportes de información: ese defecto estructural le pone en situación de neotenia o detención estacionaria en una fase incipiente del desarrollo. El vegetal sería un cristal neoténico, el animal sería un vegetal neoténico, el ser humano sería un animal neoténico ${ }^{62}$.

Un sujeto es una función de integración: para integrar algo hay que elevarse del nivel de lo que se integra. Pero los sujetos no están fuera del mundo como Dios. Están dentro del mundo: han surgido de dentro y funcionan dentro (son proyectos de un Dios inmanente). Un sujeto es la reflexión sobre sí misma de una condición de frontera: distingue los bordes de una frontera en la medida en que difieren en valor. «No puede haber distinción sin motivo, a menos que los contenidos sean vistos como difiriendo en valor. Si un contenido es de valor, se puede tomar un nombre para indicar ese valor. Entonces, la cita del nombre puede ser identificada con el valor del contenido» ${ }^{63}$. Nombres y números -medidas nominales y numerales - son designaciones de valor (y el valor es equivalente a su designación). No hay distinción - no hay fronterasi no hay un valor y no hay un valor si no hay un sujeto que lo cite: el valor es valor para alguien. Distinguir viene de «stinguere» que viene de «stylus» (=aguijón o punta acerada): distinguir es dividir el mundo trazando una raya a punta de aguijón, discontinuar lo continuo. Las distinciones han sido hechas por alguien en algún punto y en algún momento: han sido escritas sobre el cuerpo del mundo y, para que la historia del mundo prosiga, hay que borrarlas y sustituirlas por otras distinciones. Los valores no valen si no cambian: las medidas han de ser constantemente remedidas. La certeza es permanencia en un sistema de distinciones. Dudar es tener por dos («dubitare» es el frecuentativo de «duobabere»): dudar es ver los dos bordes de las distinciones ${ }^{64}$. Los sujetos son sujetos porque están sujetados: están sujetados por un sistema de

61 E. Schröprnger, What is life, Cambridge University Prees, 1944.

62 Gilbert Srmondon, L'individu et sa genèse physico-biologique, Aubier-Montaigne, 1969.

63 Spencer-Brown, op. cit., pág. 1.

64 Serres, op. cit., págs. 90-91. 
nivel más alto (hasta llegar al universo total). También sus dudas sirven al sistema: mediante ellas el sistema cambia, desplazando sus fronteras (sus distinciones y valores). Las medidas rígidas provocan el cerramiento y la muerte de los sistemas: las medidas flexibles - las dudas - amplian las aberturas de los sistemas.

\section{Tipos de dispositivos de medida}

Las segundas articulaciones corresponden al contenido, las primeras articulaciones corresponden a la expresión. Podemos clasificar a los estratos o niveles (físico, vital, social) según las modalidades de expresión: cada modalidad de expresión desarrolla un tipo de medidas. La expresión se va desterritorializando a lo largo de la evolución: a medida en que la expresión se desterritorializa se puede reterritorializar el contenido (mediante medidas cada vez más potentes, semántica y pragmáticamente).

A nivel físico, la sustancia de la expresión no es distinta de la sustancia del contenido. La expresión es coextensiva al volumen (materia amorfa) o a la superficie (materia cristalizada): el cristal introduce una frontera bidimensional en el mundo físico tridimensional (es el primer individuo). Esa frontera es el lugar de emergencia de un protosujeto (cuando la frontera pueda reflexionar sobre sí misma, habrá aparecido la vida). Pero, de momento, al no autonomizarse la expresión, no puede haber mediciones: no hay distancia, no hay diferencia. Sólo cabe la acción por contacto. No hay alternativas. Las medidas llamadas físicas son medidas realizadas por unos hombres llamados físicos: son medidas sociales (los medidores y los dispositivos de medida pertenecen al orden social). No hay nada más lejano de una máquina física que una máquina construída por el hombre - por ejemplo, un ordenador-: es el resultado de un dominio desde el orden social del orden físico (del orden dinámico y/o del orden termodinámico).

A nivel vital, la expresión se hace autónoma y lineal: la sustancia de la expresión (sema: ácidos nucleicos) se hace distinta de la sustancia del contenido (soma: proteínas) y la forma de expresión se hace lineal (linearidad de la secuencia nucleica). Ya no se trata de la relación entre un nivel molecular de contenido y un nivel molar de expresión (ya no se trata de jerarquías estructurales): hay molecular y molar, en el contenido (aminoácidos, y proteínas) y en la expresión (bases púricas y pirimídicas, y ácidos nucleicos). Las dos articulaciones construyen unidades estables y no meros estados estacionarios metaestables. Se separan los dispositivos de medida de lo medido. Surgen dispositivos permanentes de medida. A este nivel, la expresión es homoplásica: conforma el organismo pero no el medio. Se informa del medio pero no lo conforma: aún no se heredan los caracteres adquiridos. A este nivel, el organismo (o la especie a través del organismo) toma medidas de sí (a sí y sobre sí) pero no del medio ( $s i ́$ al medio, pero no sobre el medio: puede leer en el medio pero no escribir en él). El organismo está codificado, pero el medio no. 
A nivel social, pasamos de la expresión homoplástica (genética) a la expresión aloplástica (lingüística): conforma el organismo y el medio, toma medidas de sí y del medio. Se heredan los caracteres adquiridos: no por transmisión genética sino por transmisión lingüística ( $\mathrm{y}$, en general, semiótica). La linearidad espacial de los códigos genéticos se dobla con la linearidad temporal de los códigos lingüísticos (sobrelinearidad): lo que permite una sobrecodificación o síntesis formal de las sucesiones que hace posible la traducción (traducción de todos los sistemas en términos de códigos lingüísticos - ciencia-). Cuando la secuencia hablada se dobla con la secuencia escrita (scripta manent), se produce una expresión exterior al organismo (libros con mayor potencia teórica, ordenadores, con sus memorias, con mayor potencia práctica) ${ }^{65}$. Se dobla la transmisión genética con la transmisión cultural ${ }^{66}$. A este nivel, se pueden tomar medidas de (a y sobre) el universo entero: estamos en contacto con todos los puntos del espacio y con todos los momentos del tiempo ${ }^{67} \mathrm{El}$ alcance de la acción - de las medidas que se pueden tomar- se amplia en extensión y en comprensión. Se bifurca en dos dispositivos complementarios: el dispositivo-mano-herramientas ligado al contenido y el dispositivo caralenguaje ligado a la expresión. El contenido se hace tecnológico y la expresión se hace lingüística. Herramientas y lenguajes permiten, en cuando son prótesis desgajadas del organismo, proyectar la acción lejos de sí en el espacio y en el tiempo, combinaciones de herramientas permiten la constrcción de cualquier contenido y combinaciones de lenguajes permiten la construcción de cualquier expresión. El dispositivo doblemente articulado herramientas-lenguajes convierte al universo ${ }^{68}$ en un solo estrato del que se pueden tomar medidas: tomarle medidas (informarse de él) y tomar medidas sobre él (conformarlo). Tan es así que el universo - nuestro universo- está en peligro. Hemos construido objetos-mundo, objetos de la dimensión del mundo (en el espacio - cohetes interplanetarios y algún día intergalácticos- y en el tiempo - residuos no degradables y radiaciones-), que ponen en peligro el mundo. La última medida del universo que podemos tomar es su destrucción. Al fin, podemos ser dioses: un Reagan cualquiera puede igualar la potencia de Dios.

65 Deleuze y Guattari, op. cit., págs. 55 ss.

66 Con los ordenadores, la expresión deja de ser lineal. La representación no es ya un mapa o plano del mundo, sino un programa con el que se maneja el mundo: el ordenador tiene menos eficacia semántica, pero más eficacia pragmática que el libro.

67 No en todos: si la velocidad máxima de transmisión de una información, en el doble sentido de informarse de y conformar, es la velocidad de la luz, habrá puntos del espacio que no podamos alcanzar en el tiempo, de los que no podremos saber nada y a los que no podremos hacer nada. Nuestro universo puede incluir la zona temporaloide, pero no la zona spacialoide del universo (utilizando la terminología de Minkowski).

68 Universo viene de "unus+vertere" (=unificación que se hace al dar una vuelta). Lo mismo que el universo cosmológico, nuestro universo está en expansión: cada vuelta que damos - cada salto en la espiral de la evolución- construimos un nuevo universo. Cada reflexión crea un universo. 
3. Dispositivos sociales de medida

El orden social ha desarrollado dispositivos específicos de clasificación y medida: lo que los sociólogos llaman medidas de la sociedad es una aplicación reflexiva de estos dispositivos (aunque ellos sean conscientes de su semántica y no de su pragmática: saben cómo lo hacen pero no por qué lo hacen).

En los tres órdenes fundamentales de intercambio (de sujetos, de objetos y de mensajes) se han desarrollado dispositivos específicos de clasificación y medida: el dispositivo de sexualidad para el intercambio de sujetos, el dispositivo numeral de la moneda para el intercambio de objetos, el dispositivo nominal de la lengua para el intercambio de mensajes. Son dispositivos de valor de cambio: moral, económico y semántico.

En cualquier proceso de constitución de valor de cambio, un equivalente general de valor se erige como representante - de los sujetos, de los objetos, de los mensajes---: sujetos, objetos y mensajes quedan reducidos a formas relativas de valor. El falo, la moneda y la lengua serían las formas equivalentes generales. La inserción en el orden del intercambio nos constituye como sujetos: sujetos, respectivamente, de una neurosis (economía libidinal), de una ideología (economía política) y de un enunciado (economía significante) ${ }^{69}$.

La forma equivalente es el producto de la formalización de una sustancia: padre, oro y fonación/grafismo, respectivamente. Esta sustancia se formaliza a lo largo de una doble temporalidad: en la primera temporalidad hay una idealización (de la forma-fetiche a la forma-símbolo y a la forma-signo), en la segunda temporalidad hay una formalización (el valor como simple relación o razón). La primera temporalización es representable por la transformación de una curva en curva continua (sustitución de la cosa por su concepto: las formas fetiche, símbolo y signo equivalen a las formas cosa, imagen y concepto), la segunda por la transformación de la curva continua en su derivada (formalización del concepto: cuando toda sustancia ha sido eliminada de la forma - paso a límite mediante el cálculo infinitesimal- queda una forma vacía). Por eso, aunque cuando las cosas están presentes casi todas las curvas son no continuas y casi todas lar curvas continuas son no derivables, cuando las cosas son representadas todas las curvas son continuas y derivables. Predominio de la función paterna sobre la función materna $y$, en general, del paterialismo sobre el materialismo. Predominio de la economía monetaria sobre la economía natural (en la economía material sólo hay valores de uso) y, en general, de la cultura sobre la naturaleza. Predominio del significado sobre el significante y, en general, del espíritu sobre la materia.

La forma equivalente de valor se erige en unidad de medida: los sujetos, los objetos y los mensajes pueden ser medidos - como formas relativas-, de modo intensivo en relación a la forma equivalente, de modo extensivo las for-

69 Jean-Joseph Goux, Economie et symbolique, Seuil, 1973. Véase, también, Jesús IBÁÑ̂z, Más allá de la sociologia, Siglo XXI, 1979, págs. 172 ss. 
mas relativas entre sí. La primera medición es análoga (en términos de más o menos: todo lo que adopta la forma relativa es minus-válido), la segunda medición es digital (en términos de sí o no: la digitalización - necesaria para el número- permite comparar a los minusválidos entre sí). La primera forma de medición se ha desarrollado en todos los sistemas de intercambio. Las mujeres, los niños y los homosexuales son minusválidos en relación a los hombres: por eso, el término «hombre» designa sólo a los hombres-hombres, las mujeres, los niños y los homosexuales son designados con otros nombres. Las mercancías son minusválidas en relación a las monedas. Los significados son minusválidos con relación a los significantes, y todos los sistemas semióticos son minusválidos en relación a la lengua (un cuadro, una composición musical o un film valen en la medida en que pueden ser contados: de ahí el horror de los bienpensantes ante el arte no representativo). La segunda forma de medición se ha desarrollado principalmente en la economía política (en las economías libidinal y significante sólo en la medida en que los procesos de capitalización las incluyen en la economía política: el orden pasa de familiar a político y de político a económico).

Cuando nos sometemos al dispositivo de sexualidad, nos pagan en placer. Cuando nos sometemos al sistema numeral de la moneda, nos pagan en dinero. Cuando nos sometemos al sistema nominal de la lengua, nos pagan en prestigio. Los sociólogos cuantitativos reciben bastante dinero y prestigio, pero poco placer. Los sociólogos cualitativos reciben bastante placer, pero poco dinero y prestigio. Como, al fin y al cabo, estamos hablando principalmente de la sociología cuantitativa pasaremos por alto el dispositivo de sexualidad y nos centraremos - sobre todo- en el análisis de los sistemas de la moneda y la lengua.

El dispositivo de sexualidad ${ }^{70}$ es un dispositivo de medición de sí (a sí y sobre sí) y de los otros «sí» en relación a mí. La medición ha evolucionado de un nivel intensivo (recomendación de mesura) a un nivel extensivo (cuántas veces) ${ }^{71}$. Es, probablemente, el modelo general de la medición intensiva (como el dispositivo de la lengua lo sería de la medición extensiva no métrica y el dispositivo de la moneda de la métrica).

Hay un homeomorfismo entre los sistemas de la moneda y de la lengua: una moneda y una palabra son intercambiables, en la dimensión referencial por una cosa (comprada o designada), en la dimensión estructural por otras monedas o palabras (a las que equivalen por definición: «duro» equivale a «cinco

70 Michel Foucault, Histoire de la sexualité, Gallimard: 1. La volonté de savoir (1976), 2. L'usage des plaisirs (1984), 3. Le souci de soi (1984), 4. Les aveux de la chair (inédito).

71 Hace años lé en la revista Garçons et Jeune-Filles un artículo sobre relaciones pre-matrimoniales. La moral estaba completamente formalizada: se podía medir, por ejemplo, la moralidad de las caricias -exactamente qué cantidad de mal encerraban- en función de cuatro variables, tres en el espacio (zona acariciada, por debajo o por encima del vestido, con la mano quieta o moviéndose) $y$ una en el tiempo (tiempo de relaciones). 
pesetas», «hombre» equivale a «animal racional»). Hay una diferencia fundamental - sin la cual los sistemas serían isomorfos-: en la moneda hay un patrón de medida y en la lengua no ${ }^{72}$. Por eso el uso del sistema de la lengua es más especulativo que el uso del sistema de la moneda (este artículo contiene muchas especulaciones: esas especulaciones han de ser reducidas mediante una formalización, la especulación es útil en una primera fase del proceso de conocimiento como dispositivo de invención, pero en una segunda fase hay que poner en juego dispositivos de verificación y de ordenación de lo inventado). Las mediciones con la moneda son de nivel de razón: hay cero, pero la unidad es arbitraria - puede ser un duro o una peseta, puede ser también una libra-. Para racionalizar, debemos de pasar del sistema nominal de la lengua al sistema numeral de la moneda (o a un sistema isomorfo con él).

La lengua y la moneda son dispositivos de medición: la moneda es un dispositivo específico de medición (la lengua hace más cosas). Ambos han sido producidos espontáneamente por el orden social. El origen de las matemáticas está en la economía política: las geometrías han surgido para medir las propiedades ${ }^{73}$, las álgebras han surgido para contar las riquezas ${ }^{74}$. Los niños aprenden en la escuela a echar cuentas ( $\mathrm{y}$ también cuentos, en la perspectiva de la lengua). A partir del sistema económico, se descubre que otros sistemas (por ejemplo, el sistema longitud/masa/tiempo) son isomorfos con él, tienen las mismas propiedades numéricas, y se extiende la medición a esos sistemas. El sistema social sólo el isomorfo con él en la medida en que haya sido capitalizado.

El orden social es del orden del contar, primero cuentos y luego cuentas. La lengua impone ya un sistema de dictados e interdicciones: este orden es cualitativo, la moneda lo cuantifica. El capital tiende a acumularlo todo, las cosas como mercancías, las personas como esas mercancías paradójicas que son las fuerzas de trabajo. Lo sólido se transforma en fluido: en líquido por el sistema de la moneda, en gaseoso por el sistema de la lengua. Lo sólido ofrece resistencia y guarda memoria: es finitamente deformable y por tanto informable. Lo fluido no ofrece - casi- resistencia y no guarda memoria. La transformación de un sólido en líquido es una licuefacción: un capital es solvente cuando es liquidable (se liquidan todos los sólidos que interceptan los caminos: se resuelve un problema, se disuelve una manifestación, se liquida una oposición). La transformación de un sólido en gas es una sublimación: una obra de arte o un comportamiento moral son sublimes si realizan en grado supremo los valores - estéticos, morales- vigentes. El sistema de la moneda transforma en líquido, el sistema de la lengua transforma en gas (el dispositivo

72 L. HJelmslev, Ensayos lingüisticos, Gredos, 1971, pág. 77.

73 El origen está escrito en la palabra geometría.

74 En la obra de Piaget citada se puede comprobar cómo la actividad algebraica del niño se desarrolla al hilo de su actividad económica. Por ejemplo: la intuición del cero surge ante una hucha vacía, la intuición de los números negativos ante una deuda. 
de sexualidad transforma en llama). El sistema de la moneda conoce un patrón de medida (el de la lengua no): el líquido conserva su volumen (el gas no). De ahí el homeomorfismo. Para que nos pleguemos al orden sólido, tenemos que transformarnos en fluidos, en líquidos por las cuentas, en gases por los cuentos. A medida en que la capitalización económica sustituye a la capitalización semántica, las cuentas sustituyen a los cuentos (de ahí la reabsorción de las ideologías del orden del decir por las ideologías del orden del hacer: dí lo que quieras pero haz lo que debes - produce y consume-).

En la perspectiva distributiva de la investigación social, cuyo modelo general es la encuesta estadística, el orden sólido o estriaje del espacio social es patente: figurado por la matriz de datos, cada columna corresponde a un entrevistado, cada fila a una pregunta. Así se unifican las respuestas, el juego de lenguaje pregunta/respuesta (test) permite respuestas medibles y acumulables (capitalizables).

En la perspectiva estructural de la investigación social, cuyo modelo general es el grupo de discusión, la matriz sufre una expansión en las dos dimensiones - simulando un espacio más libre o más isótropo-: del individuo al grupo, del juego de lenguaje «pregunta/respuesta» al juego de lenguaje «conversación». El orden es más flexible. Una tabla de instrucción, en un cuartel, figura la situación nuclear de supeditación del hacer al decir: todos y cada uno hacen lo que el otro dice ${ }^{75}$. Cuando rompen filas, y más cuando se licencian, la supeditación del hacer de todos y cada uno al hacer del otro es más laxa (la cadena que los ata se hace elástica, hay una transformación topológica - la distancia varía pero el orden se conserva-). En cualquier momento, el soldado puede ser otra vez llamado a formar, el ex-soldado puede ser otra vez llamado a filas.

En la perspectiva distributiva, el dispositivo de captura (la red con la que se caza a los entrevistados para extraerles sus respuestas) es visible: la unidad de cuenta es manifiesta. El orden es de tipo raíz. En la perspectiva estructural, el dispositivo o red de captura no es visible (por eso, los participantes en una discusión de grupo tienen la conciencia de que hablan de lo que quieren como quieren): la unidad de cuento está latente. $\mathrm{El}$ orden es de tipo radícula ${ }^{76}$. La unidad no se constituye en el presente sino en el pasado (cuando la aparente dispersión es reducida mediante un análisis genético, como cuando la dispersión aparente de un texto se unifica a partir de la postulación subjetiva de un autor -en las interpretaciones psicologistas - o de la postulación objetiva de una situación -en las interpretaciones sociologistas-) o en el porvenir (cuando la aparente dispersión es reducida mediante un análisis estructural). En ambos casos, como eje genético o estructura profunda, la unidad funciona como límite, abortada en el presente, vale precisamente por su ausencia. La unidad se constituye, como exterioridad y trascendencia, fuera del sistema al

75 Carlos Allones, tesis de licenciatura en sociología (inédita).

76 Deleuze y Guettari, op. cit. 
que unifica o conjunta (padre muerto —o falo como significante de la falta-, moneda inconsumible, palabra vacía), «opera en una dimensión vacía suplementaria a las del sistema considerado» ${ }^{77}$. Las expansiones son bucles en el árbol (recuperables por retroacción): el grupo es un bucle en el árbol familiar, la discusión es un bucle en el árbol discursivo.

A medida en que la dimensión pragmática de los lenguajes absorbe su dimensión semántica —el sentido es pragmático y no semántico-, a medida en que la memoria depositada en dispositivos electrónicos absorbe a la memoria depositada en libros, las cuentas sustituyen a los cuentos. Las perspectivas cuantitativas de medición sustituyen a las perspectivas cualitativas.

Pero a algún nivel (a menos que los seres humanos seamos barridos de la historia) es preciso el complemento de una investigación cualitativa. La primera revolución industrial ha robotizado los procesos de ejecución. La segunda revolución industrial ha robotizado los procesos de concepción - computación-. La tercera revolución industrial está robotizando los procesos de decisión —ordenación-. La perspectiva cualitativa se retira, o se eleva, a un nivel cada vez más alto de abstracción y exige un nivel cada vez más alto de reflexión.

\section{COLOFON}

El maestro zen dice al discípulo, enarbolando un garrote: «Si dices que este palo palo es real te daré con él, si dices que no es real te daré con él, si dices que es real y no real te daré con él, y si dices que no es ni real ni no real te daré con él.» Situación aparentemente sin salida para el discípulo, pero que tiene dos salidas. Una salida semántica o del orden del decir: recitarle al maestro el tetralema. Si el discípulo sale por esta salida seguirá siendo discípulo y el maestro maestro. Una salida pragmática o del orden del hacer: quitarle el palo al maestro y partírselo en la cabeza (en general: romper el contrato de aprendizaje). Entonces no habrá ni maestro ni discípulo ${ }^{78}$.

Para quedar a salvo de las mediciones abusivas hay que medir a los medidores con la misma vara con la que nos miden. Como hizo Humpty-Dumpty.

77 Ibidem, pág. 15. La sobrecodificación se produce cuando un sistema es observado y controlado por otro sistema. La lengua común y el lenguaje matemático operan sobrecodificaciones: cada sistema es sobrecodificado desde la perspectiva de un observador humano, individual en la dimensión del habla y colectivo en la dimensión de la lengua, situado, como sujeto trascendental, al otro lado. Al estar en posición trascendental (cuya traducción analítica es el concepto de función-padre o castración, cuya traducción matemática es el concepto cantoriano de conjunto transfinito), opera como conjunto que tiene la propiedad de la reflexividad, el de poder ponerse en correspondencia con sus partes. El sujeto del conocimiento introduce la dimensión suplementaria que opera la sobrecodificación que unifica o conjunta los sistemas. La ciencia de los sistemas introduce una dimensión en los sistemas.

78 Gregory Bateson, Doble-vinculo y esquizofrenia, Carlos Lohlé, 1977. 